\title{
Beyond Trophic Factors: Exploiting the Intrinsic Regenerative Properties of Adult Neurons
}

\author{
Arul Duraikannu, Anand Krishnan, Ambika Chandrasekhar and Douglas W. Zochodne* \\ Division of Neurology, Department of Medicine, and Neuroscience and Mental Health Institute, University of Alberta, \\ Edmonton, $A B$, Canada
}

Injuries and diseases of the peripheral nervous system (PNS) are common but frequently irreversible. It is often but mistakenly assumed that peripheral neuron regeneration is robust without a need to be improved or supported. However, axonal lesions, especially those involving proximal nerves rarely recover fully and injuries generally are complicated by slow and incomplete regeneration. Strategies to enhance the intrinsic growth properties of reluctant adult neurons offer an alternative approach to consider during regeneration. Since axons rarely regrow without an intimately partnered Schwann cell (SC), approaches to enhance SC plasticity carry along benefits to their axon partners. Direct targeting of molecules that inhibit growth cone plasticity can inform important regenerative strategies. A newer approach, a focus of our laboratory, exploits tumor suppressor molecules that normally dampen unconstrained growth. However several are also prominently expressed in stable adult neurons. During regeneration their ongoing expression "brakes" growth, whereas their inhibition and knockdown may

OPEN ACCESS

Edited by:

Giovanna Gambarotta,

University of Turin, Italy

Reviewed by: Valerio Magnaghi, University of Milan, Italy Ertugrul Kilic Istanbul Medipol University, Turkey

*Correspondence: Douglas W. Zochodne zochodne@ualberta.ca

Received: 03 December 2018 Accepted: 14 March 2019 Published: 05 April 2019

Citation:

Duraikannu A, Krishnan A, Chandrasekhar $A$ and Zochodne DW (2019) Beyond Trophic Factors: Exploiting the Intrinsic Regenerative Properties of Adult Neurons. Front. Cell. Neurosci. 13:128. doi: 10.3389/fncel.2019.00128 enhance regrowth. Examples have included phosphatase and tensin homolog deleted on chromosome ten (PTEN), a tumor suppressor that inhibits PI3K/pAkt signaling, $\mathrm{Rb} 1$, the protein involved in retinoblastoma development, and adenomatous polyposis coli (APC), a tumor suppressor that inhibits $\beta$-Catenin transcriptional signaling and its translocation to the nucleus. The identification of several new targets to manipulate the plasticity of regenerating adult peripheral neurons is exciting. How they fit with canonical regeneration strategies and their feasibility require additional work. Newer forms of nonviral siRNA delivery may be approaches for molecular manipulation to improve regeneration.

Keywords: peripheral nerve, RhoA, Netrin/Unc5H, PTEN, RB1, BRCA1, APC/ $\beta$-catenin

\section{INTRODUCTION}

Favorable outgrowth of peripheral nervous system (PNS) axons after injury is often considered in comparison with that of the central nervous system (CNS) where severe barriers, even for limited outgrowth occur. In the clinical context, however, there is striking evidence for its inadequacy. Functional recovery from trauma or disease to the PNS is slow, incomplete and complicated by neuropathic pain. Long target distances, gaps from nerve transection and delayed regrowth into distal nerve territories add substantial and additional barriers to regrowth (Zochodne, 2012). Patients with severe, nominally reversible peripheral nerve disorders such as Guillain-Barre syndrome or vasculitis have prolonged, if not permanent deficits. Similarly, large proximal nerve 
lesions such as those at the brachial plexus or high sciatic nerve rarely recover completely. There are both intrinsic and extrinsic factors that act as barriers to the successful regrowth of neurons.

Following acute axonal injury to peripheral nerves, a series of active molecular events that degrade the distal axon develop. "Wallerian" degeneration refers to these degenerative events in distal nerve stumps strictly after transection whereas "axonal degeneration (AxD)" (or "Wallerian-like degeneration"), is a broader term that encompasses all forms of irreversible axon injury. While $\mathrm{AxD}$ is initiated immediately after axon injury, a series of morphological changes soon follow. There is fragmentation of axons, dissolution of their neurofilament scaffolds, proliferation and activation of Schwann cells (SCs), recruitment of inflammatory cells including macrophages, and dissolution then clearance of the myelin sheath and axon debris (Waller, 1850; Ide, 1996; Burnett and Zager, 2004; Chen et al., 2007; Zochodne, 2008; Figure 1). Following axonal degeneration, proliferating SCs organize themselves into bands of Bungner. These are tubular collections of both SC and basement membrane that serve as both guideposts and channels for newly sprouting axons. These peripheral events accompany changes in neuron perikarya and associated satellite glial cells. For example perineuronal satellite cells which surround nerve cell bodies in sensory and autonomic ganglia, begin to proliferate within a 2-3 days after peripheral axon injury accompanied by local proliferation of resident macrophages, both constituting a population of dorsal root ganglia (DRG) recycling cells (DRCCs) (Wong and Mattox, 1991; Sulaiman and Gordon, 2000; McKay Hart et al., 2002; Zochodne, 2008; Krishnan et al., 2018a).

At most steps during regeneration, there is unexpected axon hesitation. For example, axon regrowth from proximal nerve stumps after transection is delayed, slow and staggered. "Pioneer" axons, which resemble those of development are the first to emerge, but almost always follow leading SCs and their processes (Chen et al., 2005; McDonald et al., 2006). Navigation of axons across gaps that form between the proximal and distal stump is challenging and it is estimated that only one in 10 axons traverse it (Witzel et al., 2005). Distal nerve stumps over time also become inhospitable to hosting regrowing axons. This is contributed to by loss or atrophy of SCs, declines in their elaboration of SC-derived growth factors and declines in the local vascular supply (Sulaiman and Gordon, 2000; Hoke et al., 2001, 2002).

Here, we discuss why peripheral neurons do not grow as robustly as assumed. We begin with a discussion of growth factors that support the PNS, but shift our emphasis to intrinsic controls of growth within neurons and the potential to manipulate novel molecular pathways to enhance growth after injury (Table 1).

\section{EXTRINSIC SUPPORT OF REGENERATION THROUGH GROWTH FACTORS}

The discovery over the past 50 years that extrinsic molecules can influence the behavior of neurons, either during development or during adulthood was a remarkable advance. The prototypic growth factor was nerve growth factor (NGF) discovered in mouse submaxillary glands and snake venom that supported robust outgrowth of branches from sympathetic neurons. For its discovery, the Nobel prize in Medicine and Physiology was awarded to Drs Levi-Montalcini and Cohen in 1986. NGF was the first of a family of extrinsic growth factors termed neurotrophins. Several of these are discussed below (Table 1). Beyond this family, an expanded repertoire of growth factors is now available for improving the outcome of peripheral nerve trunk injury but their practical application remains problematic. Each axon subtype has a limited receptor deployment available to a given growth factor, requiring cocktails to support all classes of fibers in a nerve trunk. There also remain issues with access, timing of such delivery, where to administer them and their overall stability (Kemp et al., 2007).

\section{Neurotrophin Family Members}

\section{Nerve Growth Factor}

NGF supports the survival and subsequent differentiation of sensory and sympathetic neurons of the PNS (LeviMontalcini, 1950, 1987). In the CNS, NGF plays a role in the neurodevelopment and ongoing maintenance of basal forebrain cholinergic neurons (Dreyfus, 1989), septo-hippocampal pathways, hippocampal neurons and cortical neurons (Zhang et al., 1993; Culmsee et al., 1999a,b; Kume et al., 2000). NGF mediates its trophic effect by binding to specific receptors, tropomyosin-receptor kinase A (TrkA) and p75 neurotrophin receptor (p75 ${ }^{\mathrm{NTR}}$ ) (Hempstead et al., 1991; Chao, 2003; Huang and Reichardt, 2003). When $\mathrm{p} 75^{\mathrm{NTR}}$ is activated in the absence of Trk ligation, however, it promotes apoptosis of neurons. In the presence of Trks, p75 ${ }^{\mathrm{NTR}}$ enhances neurotrophin responses (Kaplan and Miller, 1997). After sciatic nerve injury, NGF receptor expression increased in motor neurons at spinal levels L4-L6 where it reached a maximum level between 1 and 7 days, and normalized to baseline by day 30 (Rende et al., 1992a; DiStefano and Curtis, 1994). NGF is also increased in injured distal nerve stumps (Richardson and Ebendal, 1982; Heumann et al., 1987) and it probably protects adult rat DRG neurons from retrograde cell atrophy and death following axotomy injury (Rich et al., 1987). NGF treatment to pre-injured sensory neurons in vitro, derived from young (3 months) and old (26 months) mice supports neurite outgrowth (Horie et al., 1991). Similarly, delayed administration of NGF to the sciatic nerve 3 weeks after transection restores high-affinity NGF receptor density and partially restores neuronal volume (Verge et al., 1989). Topical application of NGF (1 $\mu \mathrm{g})$ into a nerve crush site increases motor nerve conduction velocity (MNCV), and numbers of regenerating myelinated fibers (RMFs) in rat sciatic nerves (Chen and Wang, 1995). Similar benefits accrue when NGF is given by silicone chamber to injured nerves (Derby et al., 1993; Santos et al., 2017) although gradients are difficult to establish (Kemp et al., 2007).

\section{Brain Derived Neurotrophic Factor}

Perhaps the best characterized and most promising neurotrophin family member is brain derived neurotrophic factor (BDNF). 

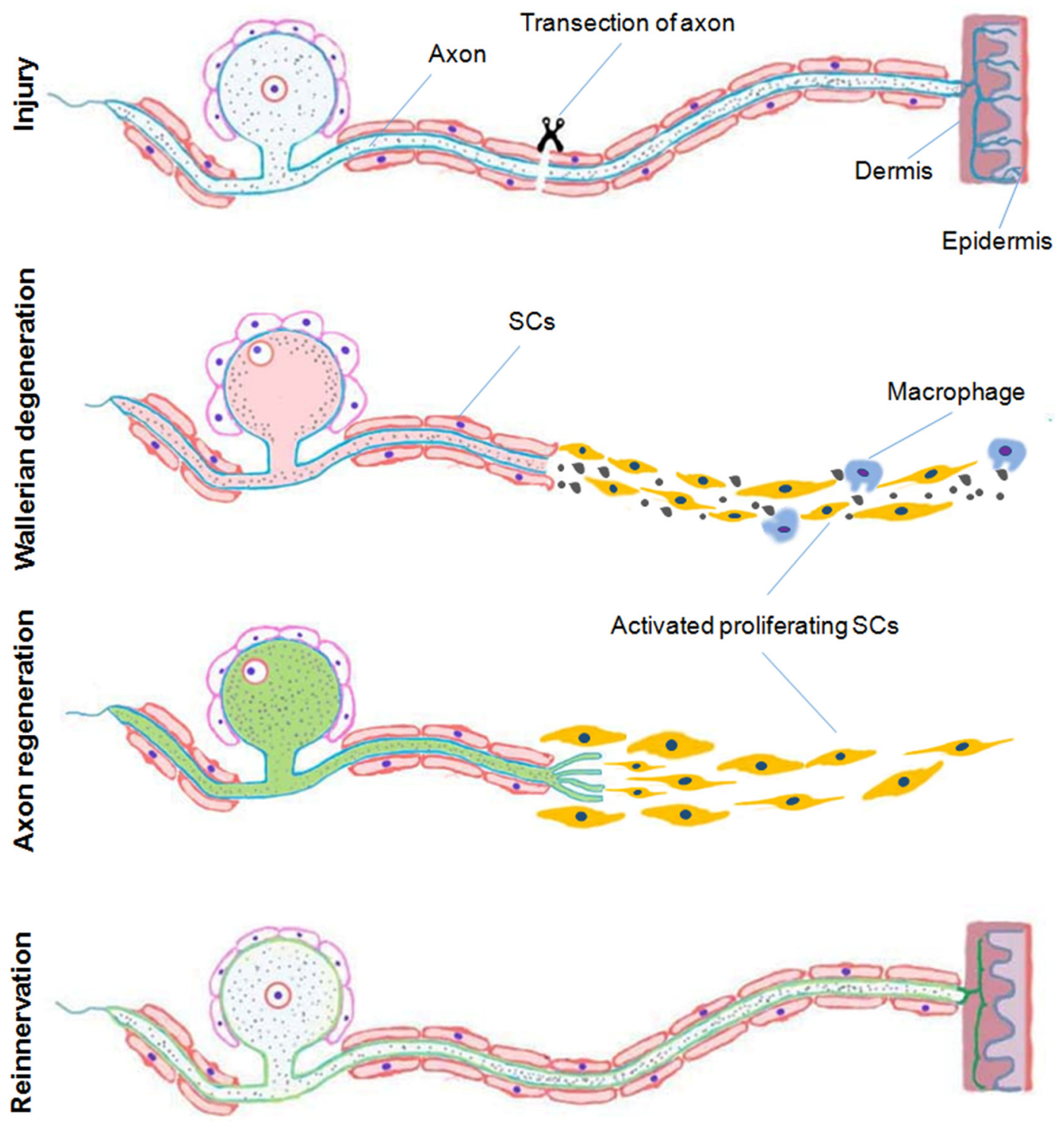

FIGURE 1 | A schematic representation of Wallerian degeneration and regeneration after peripheral nervous system (PNS) injury. In the peripheral nerve following and acute transection axonal injury, Wallerian degeneration, which takes place during few days after injury, is characterized by proliferation and activation of Schwann cells (SCs), recruitment of inflammatory cells including macrophages and dissolution and clearance of the myelin sheath and debris. Proliferating SCs respond by organizing themselves providing a pathway for newly sprouting axons during regeneration and later remyelination associated with reinnervation of the distal target tissue (Duraikannu, original illustration).

BDNF has essential roles in neuronal survival, growth and differentiation during development, and synaptic plasticity in adult peripheral neurons (Thoenen, 1995; Huang and Reichardt, 2001). As such, BDNF has been a potential candidate to promote nerve regeneration. After injury, the BDNF mRNA expression is increased in DRG, SCs and muscle fibers (Zhang et al., 2000; Fukuoka et al., 2001; Kobayashi et al., 2008). Enhanced BDNF protein expression has also been identified in DRG neurons after spinal dorsal horn injury (Fukuoka et al., 2001; Miletic and Miletic, 2002; Geng et al., 2010). More importantly, BDNF and its receptor TrkB (affinity tyrosine kinase receptor B) are robustly expressed in both
DRG sensory, and spinal motor neurons (Foster et al., 1994; Hammarberg et al., 2000) after sciatic nerve injury. Specifically, BDNF was expressed prominently in both small and medium size DRG neurons following nerve injury (Cho et al., 1998; Kashiba and Senba, 1999). Sensory-neuron derived BDNF is also transported in the anterograde direction, appearing at the injured nerve site. The levels of BDNF decline over weeks following the injury (Zhou and Rush, 1996; Tonra et al., 1998). Furthermore, BDNF and TrkB receptors are expressed in different muscles to coordinate muscle innervation and the functional differentiation of neuromuscular junctions (Chevrel et al., 2006). In contrast, following nerve injury deprivation 
TABLE 1 | A selected listing of approaches discussed in this review that promote axonal regeneration

\section{Neurotrophic factors}

Nerve growth factor (NGF)

Brain derived neurotrophic factor (BDNF)

Neurotrophin-3 (NT-3) and neurotrophin-4/5 (NT-4/5)

Ciliary neurotrophic factor (CNTF)

Leukemia inhibitory factor (LIF)

Oncostatin M (OSM)

Glial cell line-derived neurotrophic factor (GDNF)

Hepatocyte growth factor (HGF)

Cardiotrophin-1 (CT-1)

Neurturin (NRTN)

Artemin (ARTN)

Persephin (PSP)

Bone morphogenetic proteins (BMPs)

Epidermal growth factor (EGF)

Fibroblast growth factor (FGF)

Osteopontin (OPN)

Insulin

Electrical stimulation

Developmental molecules in regeneration

Unc5H inhibition

Growth cone manipulation

Inhibition of RHOA-ROK

Influence of tumor suppressor pathways during regeneration

Phosphatase and tensin homolog (PTEN)

Retinoblastoma 1 (Rb1)

APC- $\beta$-catentin pathway

of endogenous BDNF showed attenuated axon outgrowth, and reduced myelinated axon repopulation and regeneration (Song et al., 2008). Treatment with exogenous BDNF to peripheral nerves is transganglionically transported within the spinal cord (Curtis et al., 1998) and as expected, increased recovery after spinal cord injury (Song et al., 2008). In addition, single intrathecal injections of BDNF effectively produce long-lasting thermal hyperalgesia and tactile allodynia in normal mice and may play an important role in chronic pain syndromes (Yajima et al., 2002; Nijs et al., 2015; Sikandar et al., 2018). Delivery of BDNF to the hindpaw or sciatic nerve improves locomotion recovery after contusion injury (Song et al., 2008). Therefore, given these data, there is a reason to believe that BDNF may offer therapeutic benefits for peripheral nerve regeneration.

\section{Neurotrophins-3 and 4/5}

Neurotrophin-3 (NT-3) and neurotrophin-4/5 (NT-4/5), additional members of neurotrophin family, support nervous system development, survival, differentiation, and repair (Yamamoto et al., 1996). In the CNS, NT-3 prevents degeneration of noradrenergic (Arenas and Persson, 1994) and dopaminergic neurons (Hyman et al., 1994). NT-3 with or without BDNF improves axonal regeneration after spinal cord injury (Schnell et al., 1994; Xu et al., 1995; Ramer et al., 2001; Liu et al., 2016; Keefe et al., 2017). NT-4/5 stimulates axonal branching from regenerating retinal ganglion cells (RGCs; Sawai et al., 1996). In the PNS, NT-3 promotes neurite outgrowth and survival in peripheral sensory, motor and sympathetic neurons (Rosenthal et al., 1990; Henderson et al., 1993). NT-3 binds to the TrkC receptor (Katoh-Semba et al., 1996) mainly in large sensory neurons (Zhou and Rush, 1993). NT-4 at the site of sciatic nerve injury increases axon numbers, axonal diameter, myelin thickness and sciatic function index (Yin et al., 2001). NT-4/5 prevents the cell death of embryonic rat spinal motor neurons in vitro (Henderson et al., 1993). NT-3 and NT-5 stimulate functional reinnervation of skeletal muscle (Braun et al., 1996).

\section{Other Extrinsic Growth Factors}

\section{Ciliary Neurotrophic Factor}

Ciliary neurotrophic factor (CNTF) is derived from parasympathetic cholinergic neurons and is highly expressed in embryonic chick eye (Helfand et al., 1976; Adler et al., 1979; Barbin et al., 1984), adult rat peripheral nerve axons, SCs and spinal nerve roots (Williams et al., 1984; Manthorpe et al., 1986; Millaruelo et al., 1986; Rende et al., 1992b). In the CNS, CNTF is expressed in the optic nerve, mainly in astrocytes (Stöckli et al., 1991). Intravitreal injection of recombinant CNTF increased RGC survival and axon regeneration (Müller et al., 2009). In nerve, CNTF expression appears to be downregulated in the distal stump after injury site but recovered within SCs during regeneration (Williams et al., 1984; Sendtner et al., 1992). CNTF was detected in both small and large subpopulation neurons and regenerating neurites in vitro (Sango et al., 2007). Exogenous CNTF prevents degeneration of motor neurons after facial nerve lesions in neonatal rats (Sendtner et al., 1990). In addition, injured nerve sites exposed to recombinant human CNTF had greater numbers of regrowing axons in the distal stumps after injury (Sahenk et al., 1994). Topical application of CNTF to injured sciatic nerves resulted in higher MNCV indicating larger, more mature axons and higher compound muscle action potential amplitudes of the anterior tibial muscle (Zhang et al., 2004b). Likewise, CNTF null (-/-) mutant mice have reductions in axon diameter, had myelin sheath disruption, and demonstrated loss of axon-SC cell architecture at nodes of Ranvier (Gatzinsky et al., 2003). Exposure to CNTF enhanced neurite outgrowth of dissociated adult sensory neurons in vitro (Saleh et al., 2013). Finally, CNTF treatment improved sensory nerve regeneration after crush injury in diabetic rats (Mizisin et al., 2004).

\section{Leukemia Inhibitory Factor}

Leukemia inhibitory factor (LIF) supports the neurodevelopment of sensory neurons from the neural crest (Murphy et al., 1991). In the mouse DRG (embryos), LIF supports the survival of NGF non-responsive neurons and regulates sensory development in vivo (Murphy et al., 1993). LIF supports the survival of sensory neurons after sciatic nerve injury in rat pup. Interestingly, sciatic nerve injury induced LIF expression in the distal and proximal stumps and in denervated muscle fibers (Curtis et al., 1994; Kurek et al., 1996). Injured sciatic nerves treated with a silicone cuff containing LIF increased the recovery of muscle contraction, conduction velocity, myelinated fiber number and diameter (Tham et al., 1997). LIF deleted nerve segments were less supportive of axonal outgrowth (Ekström et al., 2000) and LIF knockdown mouse had impaired muscle regeneration (Kurek et al., 1997). In the CNS, deletion of LIF expression 
was associated with impaired axon sprouting of cultured RGC neurons in vitro and delayed recovery after optic nerve injury in vivo (Ogai et al., 2014).

\section{Oncostatin M}

Oncostatin M (OSM), a neuroprotective cytokine of the interleukin-6 family (Taga and Kishimoto, 1997; Heinrich et al., 1998; Senaldi et al., 1999) attenuates neuronal neuron death (Weiss et al., 2006). OSM induces signals through glycoprotein 130 (gp130) and the OSM-specific $\beta$ subunit receptor complex (Mosley et al., 1996). In the PNS, OSMR beta was expressed in small caliber non-peptidergic neurons of the dorsal root and trigeminal ganglia (Tamura et al., 2003; Morikawa et al., 2004; Morikawa, 2005). OSM mRNA expression in the nerve increased rapidly up to 14 days following injury (Ito et al., 2000). Interestingly, subcutaneous injection of OSM into the hind paw of C57BL6J wild type mice was associated with a reduction of paw withdrawal latencies to heat stimulation (Langeslag et al., 2011), indicating support for axon repair (Ito et al., 2000).

\section{Glial Cell Line-Derived Neurotrophic Factor}

Glial cell line-derived neurotrophic factor (GDNF), belongs to the transforming growth factor- $\beta$ (TGF- $\beta$ ) superfamily (Tomac et al., 1995), and enhances the survival and morphological differentiation of midbrain dopaminergic neurons (Lin et al., 1993). Recombinant GDNF promotes the survival of motor neurons (Chen et al., 2000), sympathetic neurons and enhanced neurite outgrowth in embryonic chick sympathetic neurons (Trupp et al., 1995). Local application of GDNF to the injured neonatal facial nerve prevented retrograde motor neuron loss and atrophy (Yan et al., 1995). After injury, GDNF and its receptor, GFR $\alpha-1$, mRNA levels increased in sciatic nerve (Trupp et al., 1995) distal stumps. Interestingly, GFR $\alpha-1$ was also increased in the DRG ipsilateral to the nerve injury (Hoke et al., 2000). GDNF mRNA and protein expression was upregulated in SCs $48 \mathrm{~h}$ after injury and declined to basal levels by 6 months of denervation. GFR $\alpha-1$ and GFR $\alpha-2$ mRNAs were increased only after GDNF upregulation and remained elevated as late as 6 months (Hoke et al., 2002). Pre-conditioning injury of cultured DRG neurons in vitro treated with exogenous GDNF increased neurite outgrowth (Mills et al., 2007). In addition, GDNF induced neurite outgrowth and upregulation of galectin-1 (GAL-1) through the RET/PI3K pathway in DRG sensory neurons in vitro (Takaku et al., 2013). GDNF also induced directional turning of adult neuron growth cones but only did so in the company of hepatocyte growth factor (HGF) or a phosphatase and tensin homolog (PTEN) inhibitor (Guo et al., 2014). GDNF also influences SC function (Zhang et al., 2009). In contrast, lentiviral vector-mediated GDNF overexpression for 16 weeks increased GDNF expression at regenerating sites but impaired long-distance nerve regeneration (Eggers et al., 2008; Tannemaat et al., 2008; Ortmann and Hellenbrand, 2018). Finally, GDNF may offer analgesia in animal models of neuropathic pain (Boucher et al., 2000).

\section{Hepatocyte Growth Factor}

HGF, was initially identified as a mitogen for hepatocytes (Nakamura et al., 1984, 1989). HGF interacts with c-Met receptor tyrosine kinase (Bottaro et al., 1991). In normal DRG, c-Met receptor was expressed in small and medium-size neurons and to a lesser extent in large-size neurons. However, following sciatic nerve ligation (SNL) c-Met expression increased after injury (Zheng et al., 2010). Mutations in the HGF receptor (Met tyrosine kinase), show abnormal limb innervation correlated with reductions of muscle fibers of mouse embryos (Maina et al., 1997). In normal DRG, HGF is expressed mainly in medium and large diameter neurons. Following SNL, HGF expression decreased in L4-L5 DRG neurons (Zheng et al., 2010). HGF in combination with BDNF and NT3, had no impact on DRG sensory neurite outgrowth in vitro. In contrast, HGF cooperated with NGF to enhance axonal outgrowth (Maina et al., 1997). Similarly, HGF also cooperates with CNTF positive neurons in supporting the survival and growth of parasympathetic and proprioceptive neurons (Davey et al., 2000). Repeated intramuscular injection of human HGF gene to a crush injured rat showed increased expression of HGF protein and mRNA level in DRGs associated with improvements in function and structure of the crushed nerve (Kato et al., 2005; Boldyreva et al., 2018; Ko et al., 2018).

\section{Cardiotrophin-1}

Cardiotrophin-1 (CT-1) supports the survival of developing motor neurons in vivo and in vitro (Pennica et al., 1996; Oppenheim et al., 2001). CT-1 signals by activating the leukemia inhibitory factor, gp130 (LIFR $\beta / g p 130)$ and the CT- $1 \alpha$ receptor subunit $(\mathrm{CT}-1 \mathrm{R} \alpha)$ receptor complex (Pennica et al., 1995; Robledo et al., 1997). CT-1 protects animals from progressive motor neuronopathy (PMN), a condition in which mice suffer from motor neuronal degeneration of facial motoneurons and phrenic nerve myelinated axons (Bordet et al., 1999). CT-1 also prevents deterioration in wobbler mice motor neuron disease (MND): paw position, walking pattern abnormalities, intramuscular axonal sprouting and large myelinated motor axons (Mitsumoto et al., 2001), indicating CT-1 may have therapeutic benefits in patients with MND.

\section{Neurturin}

Neurturin (NRTN) supports embryonic and adult rat midbrain dopaminergic neurons (Horger et al., 1998; Reyes-Corona et al., 2017). NRTN signaling activates Ret tyrosine kinase together with a glycosylphosphatidylinositol (GPI)-linked coreceptor (either GFR $\alpha 1$ or GFR $\beta 2$ ) (Kotzbauer et al., 1996; Golden et al., 1999). $\mathrm{NTN}^{-/-}$mice had loss of GFR $\alpha 2$-expressing neurons from DRG and trigeminal sensory ganglia (Heuckeroth et al., 1999). Neuturin and activated GFR $\alpha 2$ receptor are important for parasympathetic innervation of mucosae (Wanigasekara et al., 2004). NRTN has been shown to upregulate B1 (bradykinin) receptors expressed in isolated nociceptive neurons in mice, indicating a possible influence on pain and inflammation pathways (Vellani et al., 2004).

\section{Artemin}

Artemin (ARTN) supports the dopaminergic neurons in the rat embryonic ventral midbrain (Baloh et al., 1998b). ARTN operates through GDNF family receptor GFR $\alpha 3$, together with RET tyrosine kinase receptor (Baloh et al., 1998b). After optic 
nerve injury, ARTN receptor GFR $\alpha 3$ mRNA and protein levels increased within the first week. ARTN and its receptor (GFR $\alpha 3)$, offered neuroprotection of injured RGCs through the PI3K-AKT signaling pathway and enhanced optic nerve regeneration in rats (Omodaka et al., 2014). In the PNS, ARTN is expressed in both immature and mature myelinating SCs. After injury, ARTN was highly expressed in the distal nerve segment, indicating that it influences both developing and regenerating peripheral neurons (Baloh et al., 1998b; Ikeda-Miyagawa et al., 2015). In neonatal rat neuron cultures in vitro, ARTN supported the survival of sensory neurons derived from the DRG and the trigeminal ganglion (TG) and visceral sensory neurons of the nodose ganglion (NG; Baloh et al., 1998b). In vivo, ARTN is expressed in both large and small sensory neurons before and after injury (Baloh et al., 1998b; Wang et al., 2014). Treatment of injured peripheral nerves with ARTN enhanced motor, sensory axon regeneration including functional recovery (Jeong et al., 2008; Wang et al., 2008, 2014; Widenfalk et al., 2009; Zhou et al., 2009; Wong L. E. et al., 2015).

\section{Persephin}

Persephin (PSP) supports midbrain dopaminergic neuron survival (Milbrandt et al., 1998) in a manner similar to other neurotrophic factors like GDNF and NRN (Baloh et al., 1998a; Milbrandt et al., 1998; Leitner et al., 1999). However, PSP binds efficiently only to GFR $\alpha-4$ receptors (Enokido et al., 1998). Recent work has suggested that PSP has a neuroprotective effect in animal models of Parkinson's disease (Yin et al., 2015). In the PNS, PSP supports the survival of motor neurons but not autonomic neurons in the superior cervical ganglion (SCG), sensory neurons, or enteric neurons (Milbrandt et al., 1998).

\section{Bone Morphogenetic Proteins}

Bone morphogenetic proteins (BMPs) belong to the TGF- $\beta$ superfamily. BMPs signal using serine/threonine kinasetype I and type II receptors (Ebendal et al., 1998). BMP-2 is expressed in normal sciatic nerve. After injury, BMP-2 was localized at both distal and proximal stumps (Tsujii et al., 2009). BMP-2 improved regeneration of facial nerves and acted as a potential neurotrophic factor (Wang et al., 2007). In contrast, treatment of E10 (mouse embryos) trigeminal neurons with BMP4 in vitro resulted in neuronal death, indicating responsiveness of the neurons to BMP4 (Guha et al., 2004). However, BMP-4 promotes the survival of motor neurons and protects neurons from glutamate-induced toxicity (Chou et al., 2013). Treatment with BMP-7 improved recovery in spinal cord injured rats (Chen et al., 2018). In double-ligated sciatic nerves, BMP4 protein was expressed at both the proximal and distal portion of motor axons, indicating BMP-4 proteins were anterogradely and retrogradely transported (Chou et al., 2013). During Wallerian degeneration, BMP-7 expression was increased within proximal and distal injured nerve stumps (Tsujii et al., 2009).

\section{Epidermal Growth Factor}

Epidermal growth factor (EGF) promotes the proliferation of fibroblast and epithelial cells (Carpenter and Cohen, 1979; Plata-Salamán, 1991; Wong and Guillaud, 2004). EGF-induced neurotrophic action is mediated by activation of EGF receptor
(EGFr) and plays a vital role during the development of mouse and rat brain (Yamada et al., 1997; Wong and Guillaud, 2004; Yang et al., 2018). In the adult normal human DRG, Epidermal growth factor receptor (EGFR) is strongly expressed in the small, intermediate size neurons, satellite glial cells and SCs (Huerta et al., 1996). In the sciatic nerve, EGFr mRNA and protein are expressed mainly in both SCs and fibroblasts in rats. After transection injury, EGFr mRNA and protein levels increased in both proximal and distal nerve stumps (Toma et al., 1992). During development, EGF limited the neurite branching in DRG (Explant and dissociated) neurons in vitro (Maklad et al., 2009). Interestingly, ablation of EGFr was associated with disorganized sensory innervation in dorsal skin, indicating that EGFr is required for proper cutaneous innervations of the skin (Maklad et al., 2009).

\section{Fibroblast Growth Factor (FGF)}

Basic fibroblast growth factor (bFGF or FGF2), is a potent growth factor for mesoderm derived cells and acts as a neurotrophic factor to various neural cells. It has been found to enhance hippocampal, cerebral cortical, granule, ciliary ganglion and spinal cord neuron survival. bFGF also promotes neurite extension (Gospodarowicz, 1979; Gospodarowicz et al., 1984; Morrison et al., 1986; Walicke et al., 1986; Unsicker et al., 1987; Hatten et al., 1988; Fujimoto et al., 1997). FGF mainly mediates its trophic action by binding to membrane-bound receptors (FGF receptors) that possess tyrosine kinase activity to generate downstream signal transduction (Imamura et al., 1988; Walicke et al., 1989; Ornitz and Itoh, 2015). In the PNS, both acidic and basic fibroblast factors (aFGF, bFGF) mRNA levels were expressed in small and medium-size DRG neurons (Ji et al., 1995; Acosta et al., 2001). After 3 days of sciatic nerve injury, aFGF(FGF1) mRNA levels increase in DRG neurons but bFGF mRNA levels were upregulated in most DRG neurons but declined after 1 week (Ji et al., 1995). In addition, FGF 2 and 7 were also increased in lumbar DRG neurons but FGF 13 levels decreased after injury (Li et al., 2002). In the sciatic nerve, FGF 2 and FGF receptor (FGFR1-3) mRNA expression increased after injury (Grothe et al., 2001). Local treatment with bFGF after injury increased the number of regenerating axons. FGF receptor expression increased in the proximal and distal segments (Fujimoto et al., 1997; Archer et al., 1999; Grothe and Nikkhah, 2001; Namaka et al., 2001). Interestingly, FGF-2 overexpression generated SC proliferation, doubled the number of regenerating axons and enhanced remyelination after sciatic crush in mice (Jungnickel et al., 2006). Treatment with recombinant human FGF-2 (rhFGF-2) to a mental nerve crush injured rats had improved regeneration and sensory functional recovery (Lee et al., 2017).

\section{Osteopontin}

Osteopontin (OPN) is a secreted phosphoprotein that interacts with receptor $\alpha_{\mathrm{V}} \beta_{3}$ integrin (Liaw et al., 1995). OPN plays an important role in rat brain development (Shin et al., 1999; Lee et al., 2001). Furthermore, OPN expression was increased in pyramidal neurons in Alzheimer's disease (AD) brain in comparison to age-matched controls (Wung et al., 2007). In the PNS, OPN is expressed mainly in the larger sized DRG 
and TG neurons (Ichikawa et al., 2000). After injury, OPN was expressed in the degenerating distal nerve stump during the first day but was downregulated at day 14. Later stage after axotomy, SC-OPN was re-expressed in regenerating crushed nerves but not in permanently transected nerves (Jander et al., 2002; Wright et al., 2014).

\section{Insulin}

Insulin acts as a growth factor that supports the survival and synaptic plasticity of neurons (Fernyhough et al., 1993; Toth et al., 2006; Hoybergs and Meert, 2007; McNay et al., 2010; Singh et al., 2012b). Insulin receptor (IR) mRNA is regulated during postnatal peripheral nerve development (Shettar and Muttagi, 2012). In dissociated neurons in vitro, insulin signaling regulates neurite outgrowth (Fernyhough et al., 1989, 1993; Govind et al., 2001; Choi et al., 2005; Singh et al., 2012b). Neurons may also have the capacity to synthesize insulin (Devaskar et al., 1994; Rulifson et al., 2002). In adult DRG neurons, IR mRNA and protein levels were higher in small caliber neurons and sciatic nerves (Sugimoto et al., 2000, 2002). Similarly, insulin receptor subunit $\beta$ (IR $\beta$ ) expression was increased in sensory neurons after sciatic nerve crush injury (Xu et al., 2004) and has been identified in dermal fibers of mouse foot pads (Guo et al., 2011). In injured sciatic nerves, systemic insulin administration enhanced reinnervation of foot interosseous endplates associated with enhanced functional recovery (Xu et al., 2004). Intrathecal insulin increased calcitonin gene related peptide (CGRP) expression in DRG neurons, enhanced functional recovery of sensation and increased axon regrowth rate identified by the pinch test following sural nerve crush (Toth et al., 2006). In diabetic rats, near sciatic nerve insulin treatment enhanced local motor conduction velocities but also increased the percentage of small $(\leq 9.0 \mu \mathrm{m}$ diameter $)$ myelinated fibers within nerves exposed to it (Singhal et al., 1997). Local sub-hypoglycemic insulin has had additional impacts in diabetic models including reversal of axon atrophy after intrathecal injection, enhanced epidermal axon regrowth following local injection and improvements in neuropathy from intranasal injection (Brussee et al., 2004; Guo et al., 2011; De la Hoz et al., 2017).

\section{ELECTRICAL STIMULATION AND AXON REGENERATION}

One of the most robust empiric approaches, now with evidence of efficacy in humans, has been post-injury exogenous electrical stimulation. In work pioneered by Brushart, Gordon, Verge, Chan and others (Brushart et al., 2002; Geremia et al., 2007; Gordon et al., 2008, 2010; McLean et al., 2014; Wong J. N. et al., 2015), brief post-injury electrical stimulation enhanced the regrowth of motor and sensory axons (Al-Majed et al., 2000a; Gordon et al., 2007). While its full capabilities and exact mechanisms are not fully characterized, they include a retrograde ramp-up of regeneration-associated genes and the action of BDNF.

Work by Gordon et al. established that post-injury stimulation at $20 \mathrm{~Hz}$ for $1 \mathrm{~h}$ offered an impressive impact on regeneration. Interestingly this is a very specific outcome limited to a well-circumscribed paradigm but not effective with other tested forms of Electrical stimulation (ES). For this review, most of the citations here refer to this specific approach. ES increased the speed and accuracy of axonal regeneration and re-innervation (Al-Majed et al., 2000b; Brushart et al., 2002; English et al., 2007) and benefitted both sensory and motor re-innervation (Al-Majed et al., 2000b; Brushart et al., 2002; Geremia et al., 2007; Gordon et al., 2009; Singh et al., 2012a). In adult DRG neurons in vitro plated over stimulating microelectrodes, ES accelerated early neurite outgrowth (Singh et al., 2012a). Brief electrical stimulation then applied in vivo to the proximal injured site in mice enhanced regrowth of axons across transection sites (Singh et al., 2012a). ES accelerated the return of reflex foot withdrawal and contractile force in re-innervated leg muscles (Nix and Hopf, 1983; Pockett and Gavin, 1985). ES also increased the numbers of regenerated axon density and diameter after 8 weeks of surgery (Haastert et al., 2011), enhanced myelination and angiogenesis ( $\mathrm{Lu}$ et al., 2008; Deng et al., 2018). In post-surgical patients that had sustained complete digital nerve transection there were greater improvements in sensory re-innervation following ES (Wong J. N. et al., 2015).

ES facilitates myelination through impacts on SC polarization and BDNF (Wan et al., 2010). Along these lines, delayed brief ES increased expression of myelin basic protein (MBP) and promoted re-organization of the node of Ranvier coinciding with the early reappearance of re-myelinated axons (McLean et al., 2014). ES also accelerated the removal of myelin debris and promoted more vigorous clearance of activated macrophages from the demyelination zone (McLean et al., 2014).

In sensory neurons, enhanced BDNF immunoreactivity expression was identified after ES (Alrashdan et al., 2010). AlMajed et al. (2000a) demonstrated that 7 days after femoral nerve transection and stimulation the mRNA expression of BDNF and its receptor TrkB level had a two-fold rise within rat femoral motor neurons. In additional work, ES promoted the release of NGF from cultured SCs through calcium influx (Huang et al., 2010). ES is associated with rises in neuronal calcium content (Singh et al., 2012b) a change that might correlate with additional mechanisms of the ES response such as rises in regeneration related molecules including tubulin, Sonic hedgehog (Shh) and GAP43 mRNA (Singh et al., 2015).

\section{RESURRECTION OF DEVELOPMENTAL MOLECULES IN REGENERATION}

An important regeneration theme is the redeployment of developmental related molecules for new roles during regrowth. The netrin-Deleted in Colorectal Cancer (DCC)-Unc5H interactions are an important example.

Netrins belong to an evolutionarily conserved and developmentally important family of laminin-related proteins (Sun et al., 2011). Netrin-1 receptors include two main families: DCC, comprising DCC and neogenin, and the uncoordinated gene 5 (UNC-5) proteins (Keino-Masu et al., 1996; Ackerman et al., 1997; Leonardo et al., 1997). Ligation of 
DCC and UNC4H2 receptors by extracellular netrin-1 inhibited apoptosis. DCC and UNC5H2 are also called "dependence receptors" that trigger either survival or apoptotic signals depending on whether netrin- 1 is respectively present or absent (Mehlen and Mazelin, 2003; Mehlen and Tauszig-Delamasure, 2014). Netrin-1 up-regulation is important for neuronal navigation (Jiang et al., 2003; Cirulli and Yebra, 2007; Mehlen et al., 2011). Netrin-1 and DCC have specifically been linked to neural crest cell migration (Jiang et al., 2003).

Netrin-1 and its receptor proteins are involved in axonal guidance in C. elegans (Serafini et al., 1994; Leonardo et al., 1997) and act as a cue that is bifunctional and attracts or repels different axons. It attracts commissural axons using the DCC receptor and repels others through Unc5 receptors (Kennedy et al., 1994; Moore et al., 2007; Briançon-Marjollet et al., 2008). Moreover, its repulsive guidance may specifically be involved in DRG sensory axon fate during development (Watanabe et al., 2006; Masuda et al., 2008). In the CNS, netrin-1 is also expressed by oligodendrocytes and inhibits regeneration of adult CNS neurons that express Unc5H2 (Manitt et al., 2009). Netrin-1 may also have direct impacts on axon growth and branching (Dun and Parkinson, 2017; Boyer and Gupton, 2018). For example, netrin guides RGC axons as they navigate the visual pathway (Deiner and Sretavan, 1999) but also targets arborization of mature RGC axons. This involves DCC-dependent increases in presynaptic differentiation and dynamic branching (Manitt et al., 2009).

In the PNS, netrin-1 receptors are expressed in sensory and motor neurons, SCs and axons both intact or after injury (Park et al., 2007). DCC receptors and Unc5H2 receptor are expressed in glial cells, particularly in proximal nerve stumps following peripheral nerve injury (Webber et al., 2011). Knockdown of DCC locally, using an siRNA approach directed at the proximal stump of a transected nerve trunk impaired SC activation and outgrowing migration, and was associated with secondarily attenuated regeneration. In contrast, similar local knockdown of Unc5H2 receptors enhanced SC outgrowth and follow on axon regeneration. The overall findings indicated that the netrin-DCC receptor interaction is redeployed from development for use during adult axon regeneration. There were, however, differences between development and adult regeneration. In the former, the specific attractive netrin-DCC and repulsive netrin- $\mathrm{UnC} 5 \mathrm{H}$ interactions are among growing neurons. In the adult, this machinery is subsumed by reactive SCs but with the same direction of impact. Since axon-SC interactions are intimate and essential for overall nerve regrowth, knockdown of the Unc5H2 "brake" ultimately benefitted axon regrowth, following along outgrowing SCs. Interestingly, injury itself upregulated DCC receptors and down-regulated $\mathrm{Unc} 5 \mathrm{H} 2$ receptors providing facilitation for regrowth. Similarly, knockdown of DCC upregulated its reciprocal Unc5H2 receptor. Taken together, not only was there acquisition of attractive and repellant developmental neuronal molecules by SCs in the adult, their relationship also remained reciprocal. Exogenous netrin-1 peptides added to neurons in vitro or sciatic nerves in vivo did not impact regeneration, likely indicating sufficient endogenous levels to activate these receptors (Webber et al., 2011). However, higher concentrations of exogenous netrin-1 in adult DRG explants and dissociated DRG culture may inhibit neurite outgrowth (Park et al., 2007).

\section{GROWTH CONE GTPases: RhoA AND Rac1}

Local growth cone molecules may be the final arbiters over whether extension or advancement of axons occurs or whether they retract and withdraw. Among these molecules, a prominent role for the Rho family GTPases exists. RhoA GTPase and its downstream effector Rho-kinase (ROCK) signal an inhibitory pathway involved in cellular growth, differentiation, migration and survival (Mueller et al., 2005). RhoA is activated by GTP binding. RhoA/ROCK activation is involved in growth cone collapse and reduced axonal outgrowth in CNS neurons (Lehmann et al., 1999). Moreover, RhoA/ROCK activation has been detected in both spinal cord and optic nerve injury (Lehmann et al., 1999; Fu et al., 2016). After spinal cord injury, expression of RhoA was increased in neurons, astrocytes and oligodendrocytes (Dubreuil et al., 2003), indicating an important role in the inhibition of CNS regeneration ( $\mathrm{Hu}$ and Selzer, 2017). Thus, the ROCK inhibitor, Y27632 administered after spinal cord injury was associated with new axon sprouts in the gray matter distal to injury and improved functional recovery (Chan et al., 2005).

RhoA/ROCK impacts PNS axon regeneration. In the PNS, RhoA and ROCK1 mRNA and proteins are expressed in the dorsal root ganglion (DRG) neurons, axons and SCs of the sciatic nerve and upregulated after injury (Terashima et al., 2001; Cheng et al., 2008). Moreover activated RhoA GTPase was upregulated in proximal stumps of transected nerve trunks (Cheng et al., 2008). RhoA protein was also increased in motor neurons after mouse sciatic nerve injury (Hiraga et al., 2006; Joshi et al., 2015). Pharmacological inhibition of RhoA-ROCK, using the small molecule inhibitor HA1077 promoted neurite and axonal outgrowth of DRG neurons in vitro. Furthermore, when the ROCK inhibitor was applied to the tip of the sciatic nerve injury site, the number of outgrowing axons and associated SCs was enhanced (Cheng et al., 2008). RhoA GTPase also is involved in growth cone behaviour of PNS neurons. Specifically, application of a ROCK inhibitor induced growth in sensory neuron growth cones (Guo et al., 2014). Hiraga et al. (2006), noted that the ROCK inhibitor (fasudil) increased amplitudes of distally evoked compound muscle action potentials after axonal injury. Along with these physiological benefits, the agent increased numbers and caliber of regenerating axons indicating a role in promoting axon maturation through ROCK inhibition.

\section{A ROLE FOR TUMOR SUPPRESSORS IN NEURONS: PTEN IS AN INTRINSIC BLOCKER OF AXON REGROWTH}

PTEN is a tumor suppressor that converts phosphatidylinositol $(3,4,5)$-triphosphate (PIP3) into phosphatidylinositol (4,5)biphosphate (PIP2). On inactivation of PTEN, PIP3 accumulates, thereby phosphorylation activating Akt whereas pAkt 
subsequently inhibits GSK3 $\beta$, itself an inhibitor of axon growth. Knockdown of PTEN and activating the PIP3/Akt pathway is closely linked to proliferation, cell survival, increased cell size and epithelial polarity. Mutations in PTEN are found in malignant glial brain tumors (Ali et al., 1999; Broderick et al., 2004). Loss of heterozygosity of PTEN is observed in human malignancies especially endometrial and ovarian cancer, late-stage metastatic tumors and others (Li and Sun, 1997). Inactivation of a single PTEN allele increases cell proliferation and cell survival and reduces apoptosis (Di Cristofano et al., 1999; Podsypanina et al., 1999). Accordingly, PTEN has many roles in the nervous system during development and adulthood (Kath et al., 2018). Recent studies have demonstrated that neurotrophin-related growth and differentiation is specifically inhibited by PTEN overexpression (Musatov et al., 2004). Conditional deletion of PTEN in the developing hippocampus and cortex is associated with neuronal hypertrophy and behavioral alterations that model human autism (Kwon et al., 2006). On the other hand, PI3K activation regulates neuronal differentiation, survival migration, extension and guidance (Brunet et al., 2001; Rodgers and Theibert, 2002; Arimura and Kaibuchi, 2005; Chang et al., 2006).

PI3K/Akt signals are expressed and activated during axon regeneration. For example, knockdown of PTEN by siRNA increased neuronal polarity and axonal outgrowth in hippocampal neurons in vitro (Jiang et al., 2005). PTEN deleted mice had increased RGC survival and extended robust long-distance axon regeneration after 14 days of optic nerve injury. Inactivation of PTEN leads to activation of PI3K, pAkt and mammalian target of rapamycin (mTOR) signaling in CNS neurons. Studies from several models (C. elegans to mammalian neurons) have identified a role for $\mathrm{PI} 3 \mathrm{~K}$ in asymmetric signaling and its impact on orienting polarized outgrowth during axonogenesis (Yoshimura et al., 2005; Adler et al., 2006). PTEN knockdown through enhanced mTOR activity increased RGC survival and axon regeneration whereas rapamycin blocked mTOR activity and attenuated regeneration. Further, axotomy in RGCs markedly reduced pS6 levels possibly accounting for the limited CNS regeneration after crush injury (Park et al., 2008). S6 ribosomal kinase 1 is targeted by the mTOR pathway, and its phosphorylation is indicative of mTOR activity (Kim et al., 2016). Similarly, PTEN deleted mice had improved repair of the corticospinal tract (CST) of spinal cord injury mice (Geoffroy et al., 2016). Inhibition of PTEN improves outcome in experimental spinal cord injuries, with lesser motorneuron death, greater tissue sparing and smaller cavity formation (Walker et al., 2012).

PTEN knockdown is associated with substantial benefits following peripheral nerve injury. PTEN is expressed widely in sensory and motor neurons but there is intense expression among small caliber IB4 nonpeptidergic DRG neurons. Paradoxically its levels rise after nerve injury. PTEN is also expressed in SC and in regrowing injured axons (Christie et al., 2010). Local inhibition using either the pharmacological inhibitor $\mathrm{BpV}(\mathrm{pic})$ or siRNA knockdown enhances axon

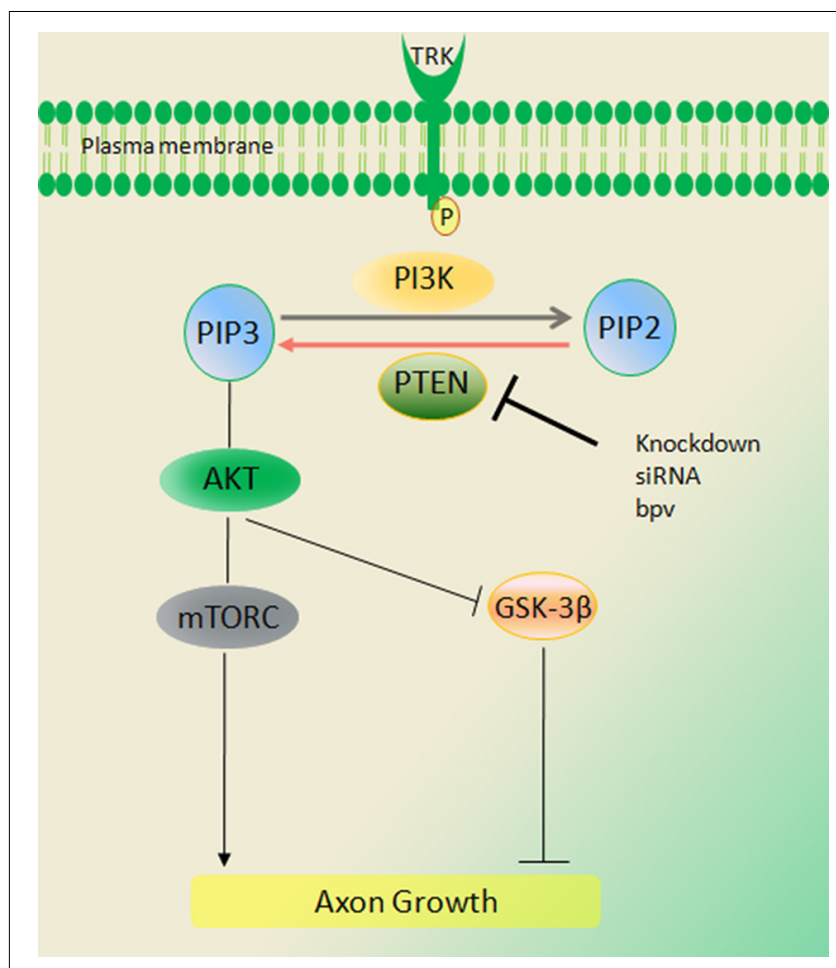

FIGURE 2 | Signaling of the phosphatase and tensin homolog deleted on chromosome ten (PTEN)/PI3K/Akt pathway. PTEN converts phosphatidylinositol $(3,4,5)$-triphosphate (PIP3) into phosphatidylinositol $(4,5)$-bisphosphate (PIP2), thus inhibiting Akt activation and peripheral nerve regeneration. Activation of PI3K and Akt signals through deletion of PTEN [BPV (pic) or siRNA] increases regeneration of axons in injury. These impacts appear to be independent of mammalian target of rapamycin (mTOR) but require the activity of PI3K and Akt (Duraikannu, original illustration).

outgrowth as evaluated in both in vitro and in vivo analysis (Figure 2; Christie et al., 2010). PTEN knockdown using siRNA was accomplished without a viral vector. In the PNS these impacts appear to be independent of mTOR but require the activity of PI3K and Akt.

PTEN may influence distal regenerative events within growing axons through central rather than peripheral modulation of cellular machinery. For example, local exposure of adult growth cones to gradients of the PTEN inhibitor, BpV (pic) did not have significant impacts on growth cone turning, unless combined with a local growth factor. However, when inhibitory gradients were instead directed at the perikarya of in vitro adult sensory neurons, there was a striking rise of distal outgrowth in distal branches growing in directions unrelated to the inhibitory gradient. These data suggest that PTEN modulation is a central deterministic signal that instructs distal growth cone behavior (Christie et al., 2010).

In a mouse spinal muscular atrophy (SMA) model, knockdown of PTEN rescued defects in axon length, growth cone structure and overall survival (Ning et al., 2010). In a chronic diabetic neuropathy model, with documented regenerative failure, PTEN levels in motor and sensory neurons were upregulated (Singh et al., 2014). In keeping with this finding, PTEN knockdown rescued the regenerative deficit. 


\section{A FURTHER TUMOR SUPPRESSOR AND ITS IMPACT ON ADULT NEURONS: RETINOBLASTOMA 1}

The retinoblastoma tumor suppressor Retinoblastoma 1 (Rb1) operates at the core of the cell cycle pathway. Its mutations are associated with childhood retinoblastoma tumors. Rb1 is linked to neuronal fate, regulating proliferation and migration of neuronal progenitors during brain development (Slack et al., 1998; Ferguson et al., 2002, 2005; McClellan et al., 2007; Andrusiak et al., 2010). In the canonical pathway, Rb1 regulates cell cycle progression by binding and signaling through the E2F family of transcription factors. The operational status of $\mathrm{Rb} 1$ protein depends on its phosphorylation status, in turn mediated by the cyclin/cyclin-dependent kinase (CDK) complex (Giacinti and Giordano, 2006).

Deletion of $\mathrm{Rb} 1$ is a frequent and early molecular hallmark of cancer. Specifically, individuals with germ-line Rb1 mutations are at risk of developing trilateral retinoblastoma, a pediatric intracranial neuroblastic tumor (Jakobiec et al., 1977; Marcus et al., 1998). Rb null mice die as embryos by E15 from hematopoietic and neurological abnormalities linked to the failure of cells to permanently withdraw from the cell cycle (Clarke et al., 1992; Jacks et al., 1992; Lee et al., 1992). Conditional deletion of $\mathrm{Rb} 1$ in the embryonic retina display ectopic division and apoptosis of developing retinal transition cells (MacPherson et al., 2004; Zhang et al., 2004a). Rb1 functions within RGC axons, such that its absence is associated with retinal and midline pathfinding errors, leading to aberrant tectal innervation. In sensory ganglia, extensive loss of sensory neurons and expression of TrkA, B neurotrophin receptors was associated with Rb1 deletion during development (Lee et al., 1992).

$\mathrm{Rb}$ deletion induces cell cycle re-entry in several systems (Sage, 2012), including mouse embryonic fibroblasts (MEFs; Sage et al., 2003), mammalian muscle cells (Zacksenhaus et al., 1996; Pajcini et al., 2010) and adult cortical neurons (Andrusiak et al., 2012). In contrast, loss of $\mathrm{Rb}$ is capable of driving mutated SC growth through a signaling pathway distinct from PI3-AKT-mTOR and using an E2F-independent mechanism (Collins et al., 2012).

As discussed, previous studies indicate that the PI3K/Akt signaling pathway influences axon outgrowth and neuronal plasticity and that these roles overlap with protection and survival. In postmitotic adult injured neurons, Rb1 may influence the downstream PI3K-Akt pathway on growth, a pattern resembling the impact of PTEN (Christie et al., 2014). Following sciatic nerve injury, $\mathrm{Rb}$ was robustly expressed in neurofilament labeled DRG neurons and axons, despite its role as an inhibitor of sensory neuron growth after injury. Like $\mathrm{PTEN}$, the $\mathrm{Rb} 1$ protein paradoxically rises following injury and may also operate downstream of Raf-MEK and the PI3K-Akt pathway. In vitro knockdown of $\mathrm{Rb}$ using siRNA increased neurite outgrowth and length in dissociated adult sensory neurons (Christie et al., 2014). As in the PTEN knockdown studies and subsequent adenomatous polyposis coli (APC) work described below, the approach used nonviral methods to achieve knockdown. In addition, silencing of $\mathrm{Rb}$ protein enhanced neurite branching in both uninjured and injured DRG neurons. These actions were abrogated with concurrent knockdown of the Rb1 effector, E2F1. E2F1 operates as a divergent transcription factor and stimulates transcription and neuronal plasticity. In adult neurons, knockdown of Rb1 was not associated with cell death with no impact on the expression of activated caspase-3 or DNA damage markers (phosphohistone H2A.X). In vivo local knockdown at a nerve crush site enhanced regeneration of axons and promoted functional recovery in injured mice (Christie et al., 2014).

\section{BRCA1 PROTECTS REGENERATING NEURONS}

Breast cancer susceptibility protein 1 (BRCA1), a tumor suppressor, plays a critical role in DNA repair and CNS development (Miki et al., 1994). BRCA1 is expressed in proliferating embryonic and adult neural stem cells (Korhonen et al., 2003). Deleting BRCA1 in the CNS, results in various abnormalities in brain development and overall brain volume is severely reduced, apparent in the neocortex, cerebellum, and olfactory bulbs (Gowen et al., 1996; Pulvers and Huttner, 2009; Pao et al., 2014). BRCA1 is also involved in rat RGC neuron survival and DNA repair after exposure to ionizing radiation in vitro (Wang et al., 2018). In spinal cord injury, BRCA1 is highly expressed in spinal microglia (Noristani et al., 2017). In the PNS, BRCA1 is expressed in DRG, sciatic nerve and SCs in adult rat and after injury, is expressed at high levels in both proximal and distal nerve. BRCA1 expression was identified in injured SCs, neuronal satellite cells and axons and it translocated to neuronal nuclei. Interestingly, BRCA1 supported the regenerative phenotype in neurons such that its knockdown was associated with a decrease in neurite outgrowth and reduced branch length of injured sensory neurons in vitro (Krishnan et al., 2018b). In SCs BRCA1 depletion impaired SC proliferation. BRCA1 modulates oxidative stress in injured sensory neurons and SCs (Krishnan et al., 2018b). It appears critical in modulating DNA repair by preserving DNA integrity in neurons, particularly after injury through its nuclear enrichment. The role of BRCA1 in sensory neurons has taught us that DNA repair may be an intrinsic element of their acquisition of a regenerative phenotype. In addition to BRCA1, adult peripheral neurons constitutively express additional DNA repair molecules, such as 53BP1, important for their ongoing wellbeing.

\section{APC AND ITS $\beta$-CATENIN PARTNER}

The parallel but thus far largely unconnected impact of two critical tumor suppressor pathways, PTEN and Rb1, on postmitotic adult sensory neurons was remarkable. BRCA1 appears to have a different operational mandate in neurons. Given all of these findings, however, we hypothesized that exploitation of a range of tumor-related pathways might be a general property of regenerating adult neurons. Along these lines, we chose to study yet an additional tumor suppressor pathway, APC and 


\section{$\mathbf{A}$}
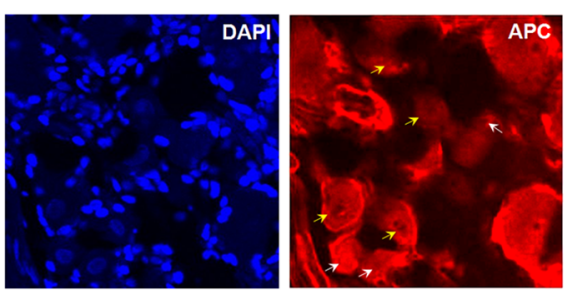

c
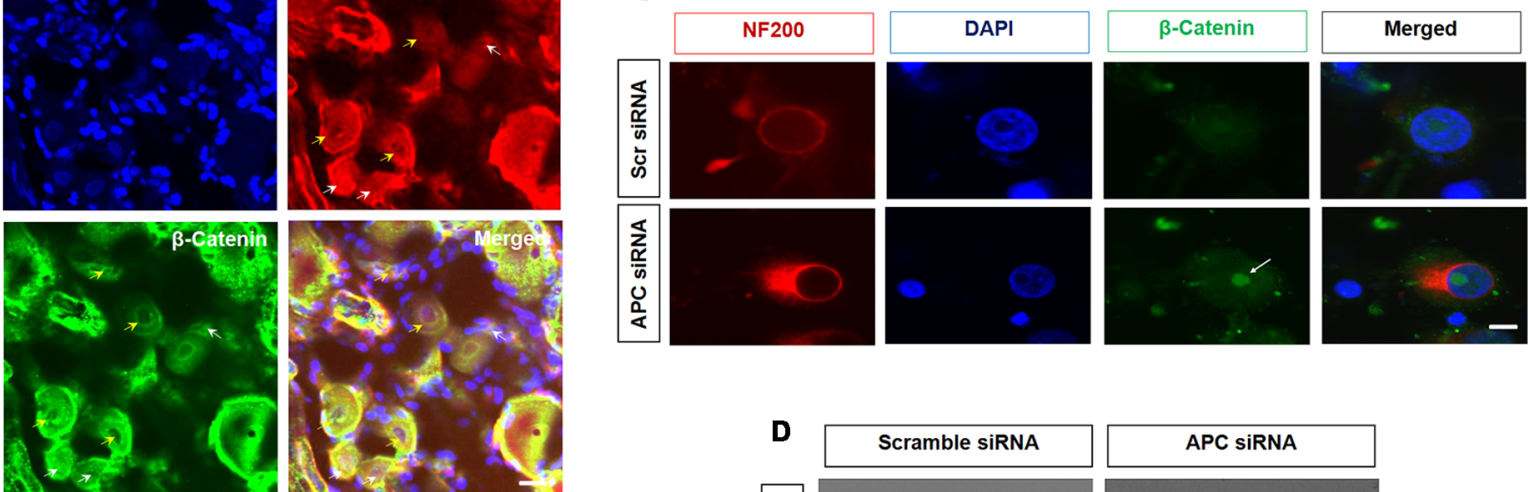

B
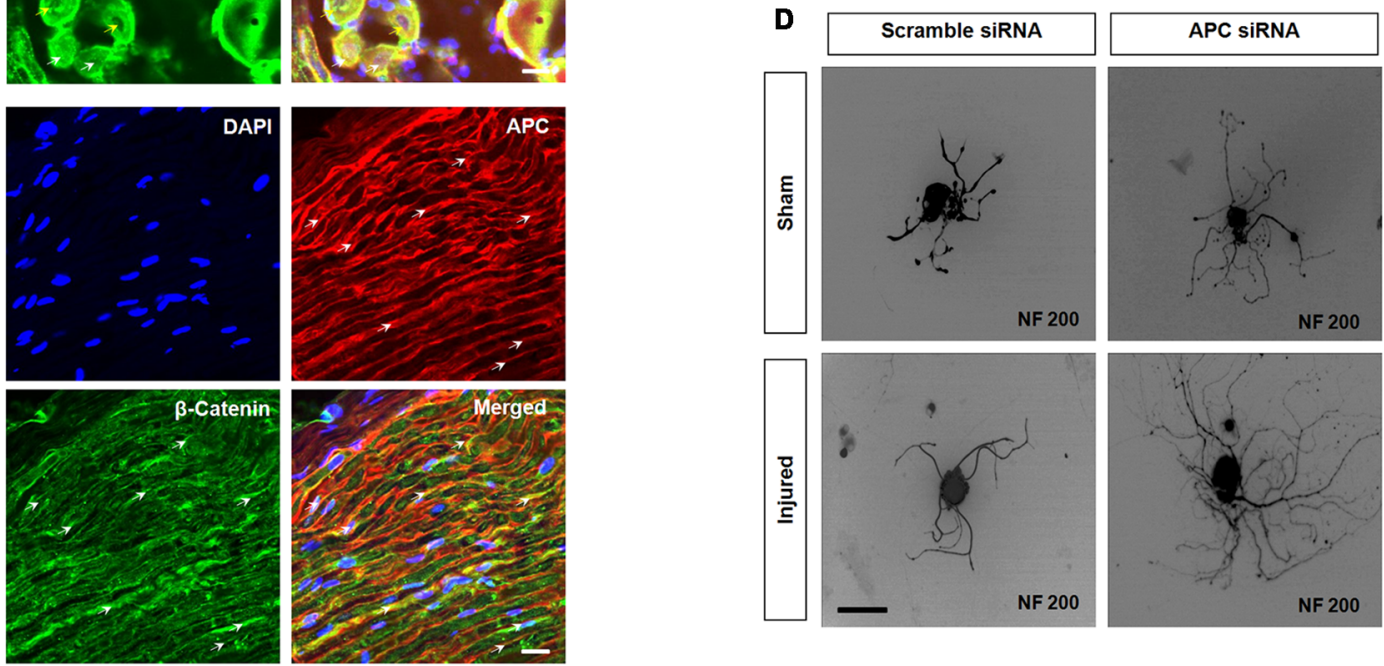

FIGURE 3 | Adenomatous polyposis coli (APC) and $\beta$-Catenin in sensory neurons. (A,B) APC and $\beta$-Catenin co-localize in the dorsal root ganglia (DRG) and sciatic nerve. (A) APC is expressed in $\beta$-catenin positive DRG neurons. Importantly, APC is prominently co-localized with $\beta$-Catenin in a subset of small (white arrow) and medium size (yellow arrow) uninjured DRG neurons. (B) Longitudinal section of uninjured sciatic nerve. APC (red, white arrow) and $\beta$-catenin (green, white arrow) showing colocalization. (C) Z stacks confocal picture demonstrate the nuclear localization of $\beta$-catenin in cultured DRG neurons with APC knockdown when compared to those exposed to scrambled control siRNA in vitro. Scale bar $=50 \mu \mathrm{m}$. (D) Silencing APC by siRNA increased neurite outgrowth in cultured DRG neurons when compared to scrambled siRNA in both sham sciatic injury and sciatic axotomy pre-conditioning injury. Scale bar $=50 \mu \mathrm{m}$ (Duraikannu, original illustration).

its $\beta$-catenin pathway, important culprits in the development of colorectal tumors.

Wnt/ $\beta$-catenin signaling plays a significant role in neurodevelopment and neuronal plasticity (Tawk et al., 2011). The Wnt/ $\beta$-catenin pathway contributes toward oligodendrocyte and SC myelination; the expression of myelin genes, SC migration, and their proliferation in the PNS (Tawk et al., 2011). In Wnt signaling, $\beta$-catenin is an important multifunctional transcriptional protein, binding to APC and GSK3 $\beta$. A remarkable feature of $\beta$-catenin protein is that it promotes cell proliferation and resistance to apoptosis (Clevers, 2006; Shelton et al., 2006). APC is a binding partner to $\beta$-catenin that results in a destruction complex involving proteasomal degradation and transcriptional inhibition (Kimelman and $\mathrm{Xu}$, 2006). Through this interaction, APC is involved in proliferation, apoptosis, cell adhesion, and migration (Hanson and Miller, 2005). APC activities also play a vital role in both the developing as well as adult nervous system (Bhat et al., 1994). APC is expressed in neurites of neuroblastoma cells and cortical neurons (Morrison et al., 1997a,b). Loss of APC enhances $\beta$-catenin accumulation in the nucleus with its transcriptional partner T cell factor/lymphoid enhancer factor (TCF/LEF).

$\beta$-catenin expression influences neural proliferation and neuronal differentiation (Patapoutian and Reichardt, 2000) and it is involved in hippocampal neurogenesis (Peng et al., 2009). Furthermore, $\beta$-catenin phosphorylation at residue Y654 and Y142 and its nuclear localization increases axon growth and branching in hippocampal neurons through TCF $4 / \beta$ dependent transcription (David et al., 2008). In post-mitotic neurons, it is involved in dendritogenesis, synaptogenesis and synaptic formation (Peng et al., 2009). Both Wnt and $\beta$-catenin combined regulate synaptic plasticity and axonal growth. In CNS neurons, $\mathrm{N}$ and $\mathrm{C}$-terminal domains of $\beta$-catenin are involved in cell-cell adhesion and promotion of axonal branching (Elul et al., 2003). Increased expression of $\beta$-catenin and Wnt were observed after spinal transection in adult zebrafish and 

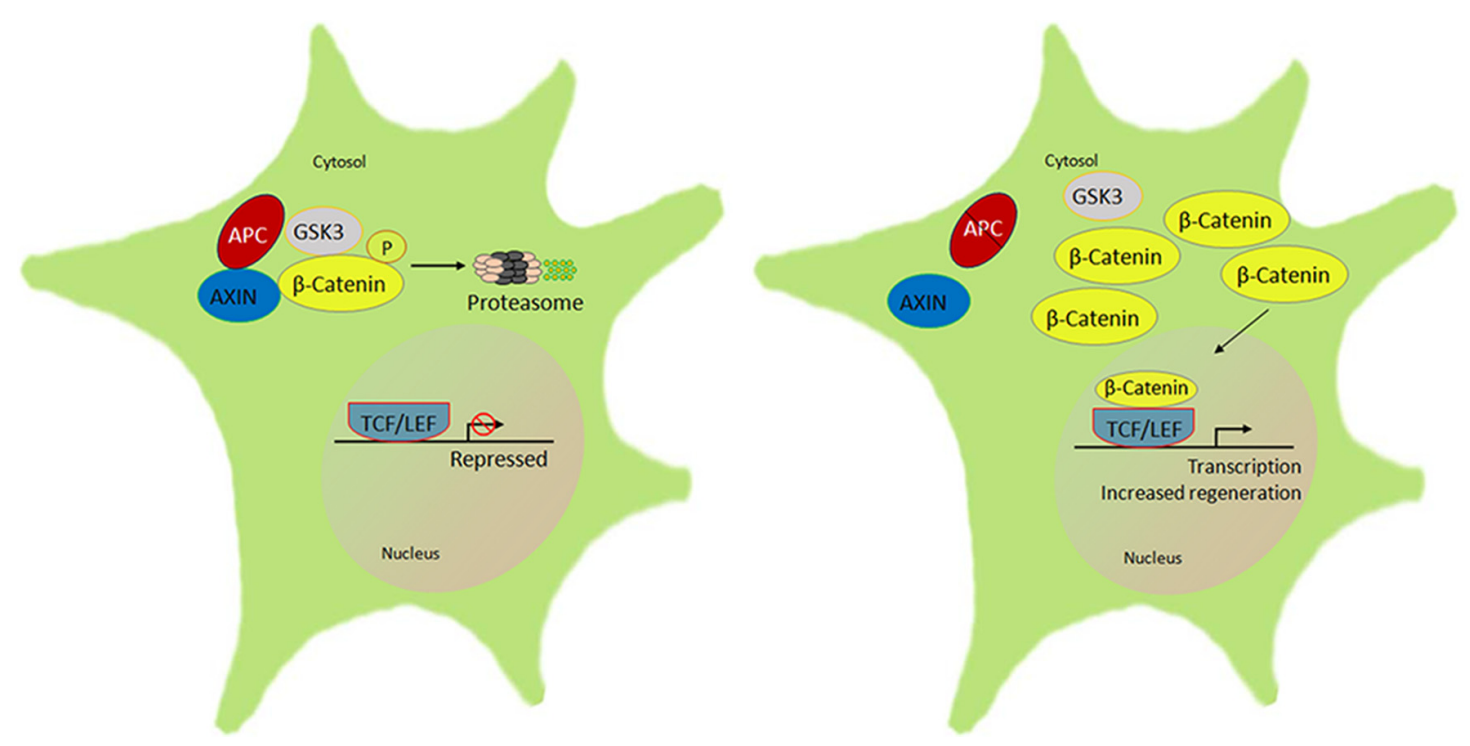

FIGURE 4 | Schematic of the $\beta$-catenin-lymphoid enhancer-binding factor/T cell factor (LEF/TCF) signal pathway that regulates peripheral neuron regeneration by APC knockdown. There is normally interaction of APC with AXIN and GSK3 that phosphorylates $\beta$-catenin to be rapidly degraded by the ubiquitin proteasome. In the absence or knockdown of APC signal with an altered AXIN-GSK3 $\beta$ complex, $\beta$-catenin accumulates and forms a complex with LEF/TCF in the nucleus, which initiates transcription of downstream target genes, in turn to promote regeneration (Duraikannu, original illustration).

correlated with axonal regeneration and improved functional recovery (Strand et al., 2016). With spinal cord lesions, Wnt/ $\beta$-catenin signaling also regulates collagen type XII alpha 1 chain (col12a1) transcription and synthesis of Collagen XII by non-neuronal cells such as fibroblasts for the extracellular matrix (ECM). These actions promoted axon regeneration and functional recovery (Wehner et al., 2017). Knockdown of $\beta$ catenin showed a delay in axonal sorting whereas gain-offunction of $\beta$-catenin mutations resulted in accelerated sorting (Grigoryan et al., 2013).

In adult DRG sensory neurons, $\beta$-catenin was expressed widely among all sensory neurons including neuronal nuclei, and cytoplasm and was also identified in perineurial satellite cells. Axonal injury results in reduced $\beta$-catenin expression in neuronal nuclei, satellite cells and sciatic nerves. In contrast, its binding partner APC was reciprocally increased following axotomy injury. Notably, after injury, expression of APC was prominent within slower growing small nonpeptidergic IB4 DRG neurons and SCs, in a remarkable similarity to PTEN expression. Furthermore, the intensity of APC expression increased in motor neurons and regenerating axons. The rises of APC, considering its role to inactivate transcriptional-related targets, indicated that it might act as a regenerative "brake" on neurons. Indeed, both the APC and $\beta$-catenin partners are combinatorially expressed in DRG neurons and their axon branches (Figure 3). Overexpression of APC interacts with $\beta$-catenin to enhance proteasomal degradation and attenuate transcription. In sensory neurons, knockdown of APC increased $\beta$-catenin nuclear accumulation, was associated with upregulation TCF and lymphoid enhancing binding factor (LEF) transcription factors (Figure 4). In addition, knockdown of APC in adult DRG neurons increased neurite outgrowth of both uninjured and preconditioned neurons (Duraikannu et al., 2018). Narciso et al. (2009), showed that $\beta$-catenin expression increased in Galectin-3 knockout mice associated with enhanced neuronal survival and axon regeneration after traumatic nerve lesions. Furthermore, interactions between $\beta$-catenin and TCF3 were required for SC myelination in vivo (Tawk et al., 2011). Inhibition of $\beta$-catenin and TCF activity impaired neurite outgrowth in DRG neurons in vitro (Duraikannu et al., 2018). In vivo, local knockdown of APC following nerve trunk crush injury using siRNA increased the repopulation of myelinated axons and was associated with improved indices of functional recovery. In keeping with the reciprocal actions of these partners, knockdown of APC led axons and SCs to express higher levels of $\beta$-catenin in vivo. Moreover, $\beta$-catenin appears to be required for SC proliferation in vitro, a critical partnering step in nerve regeneration (Narciso et al., 2009).

Overall, manipulation of the APC- $\beta$-catentin pathway has provided yet another example of how plasticity molecules are expressed in apparently stable and hard-wired neural systems. However, after injury, they play a role in supporting the plasticity essential for regeneration. In the case of APC, knockdown of its inhibitory impact releases $\beta$-catenin transcriptional activation required to support repair and outgrowth. Like PTEN and Rb1, APC is a new and important tumor suppressor in neurons that normally suppresses their growth. Whether this approach offers synergy with other tumor suppressor pathways is unclear at this time.

\section{CONCLUSIONS}

The primary goal of many endpoints in the clinical treatment of nerve injury and neuropathies is to identify improved functional 
recovery. Here, we identify how that may be accomplished through the actions of neuronal growth factors but more recently by manipulating the intrinsic growth properties of adult neurons. These approaches operate downstream of growth factors, that have the potential for off-target actions and that have impacts limited to specific subtypes of neurons. Exogenous ES activates neuronal regenerative progress through a "brute force" reset of intrinsic neuron properties that recapitulates their injury response. By doing so, the approach exploits the known property of previously injured neurons to ramp up their regenerative machinery, the "preconditioning" response. Resurrection of developmental pathways to enhance regeneration in adults likely has more room for investigation. Recognition that the array of receptors and expression patterns of neurons differs between development and adulthood is essential toward further understanding of their potential role. Re-appropriation of pathways used by neurons in development by glial cells, as described with netrin-DCC-Unc5h, is an important example of this.

Here, we focus most of this review on novel intrinsic pathways that have remarkable impacts on regrowth, downstream from growth factor receptors. That all three pathways described here influence the development of neoplasms should not be seen as a disincentive for further consideration. It is unlikely that anatomically restricted administration and temporary use of knockdown during regeneration would replicate the complex and multistage prolonged processes required for oncogenesis. In the case of BRCA1, ongoing DNA repair during neuron reprogramming toward a regenerative state may be essential. Further work is required over how the growth pathways presented here, and very likely additional neuron growth pathways interact. It is not known whether they

\section{REFERENCES}

Ackerman, S. L., Kozak, L. P., Przyborski, S. A., Rund, L. A., Boyer, B. B., and Knowles, B. B. (1997). The mouse rostral cerebellar malformation gene encodes an UNC-5-like protein. Nature 386, 838-842. doi: 10.1038/386838a0

Acosta, C. G., Fábrega, A. R., Mascó, D. H., and López, H. S. (2001). A sensory neuron subpopulation with unique sequential survival dependence on nerve growth factor and basic fibroblast growth factor during development. J. Neurosci. 21, 8873-8885. doi: 10.1523/jneurosci.21-22-08873.2001

Adler, C. E., Fetter, R. D., and Bargmann, C. I. (2006). UNC-6/Netrin induces neuronal asymmetry and defines the site of axon formation. Nat. Neurosci. 9, 511-518. doi: 10.1038/nn1666

Adler, R., Landa, K. B., Manthorpe, M., and Varon, S. (1979). Cholinergic neuronotrophic factors: intraocular distribution of trophic activity for ciliary neurons. Science 204, 1434-1436. doi: 10.1126/science.451576

Ali, I. U., Schriml, L. M., and Dean, M. (1999). Mutational spectra of PTEN/MMAC1 gene: a tumor suppressor with lipid phosphatase activity. J. Natl. Cancer Inst. 91, 1922-1932. doi: 10.1093/jnci/91.22.1922

Al-Majed, A. A., Brushart, T. M., and Gordon, T. (2000a). Electrical stimulation accelerates and increases expression of BDNF and trkB mRNA in regenerating rat femoral motoneurons. Eur. J. Neurosci. 12, 4381-4390. doi: 10.1111/j.14609568.2000.01341.x

Al-Majed, A. A., Neumann, C. M., Brushart, T. M., and Gordon, T. (2000b). Brief electrical stimulation promotes the speed and accuracy of motor axonal regeneration. J. Neurosci. 20, 2602-2608. doi: 10.1523/jneurosci.20-0702602.2000

Alrashdan, M. S., Park, J. C., Sung, M. A., Yoo, S. B., Jahng, J. W., Lee, T. H., et al. (2010). Thirty minutes of low intensity electrical stimulation promotes nerve operate synergistically with a downstream common impact on PI3K-pAkt signaling, an unequivocal and critical pathway that supports regrowth. It is also yet to be determined whether manipulation of intrinsic growth pathways might be coupled with added growth factors. Finally, the use of nonviral siRNA delivery has been an important part of regenerative studies using in vivo models. The elimination of viral delivery constructs will prove to be a major advantage to its use in humans and builds on the recognition that there is considerable extracellular trafficking capability in using siRNA. We have, for example, shown that siRNAs are routinely taken up by distal axons and retrogradely transported to their perikarya to knockdown "central" cellular gene expression. Improved approaches to enhance the stability of applied siRNAs and their access to penetrate the blood-brain barrier will be very welcomed.

\section{AUTHOR CONTRIBUTIONS}

$\mathrm{AD}$ : collated background literature, prepared the figures and wrote initial and revised versions of the manuscript prior to submission. DZ: the scope of the review article, wrote portions of the manuscript, and edited all versions prior to submission, including the final submitted version. AK and AC: contributed to the experimental work reviewed in this article, reviewed the intellectual content of the article and edited the final version.

\section{ACKNOWLEDGMENTS}

The review is based on work funded by the Canadian Institutes of Health Research. The authors are members of the Neuroscience and Mental Health Institute, University of Alberta.

regeneration after sciatic nerve crush injury in a rat model. Acta Neurol. Belg. $110,168-179$

Andrusiak, M. G., McClellan, K. A., Dugal-Tessier, D., Julian, L. M., Rodrigues, S. P., Park, D. S., et al. (2010). Rb/E2F regulates expression of neogenin during neuronal migration. Mol. Cell Biol. 31, 238-247. doi: 10.1128/MCB.00378-10

Andrusiak, M. G., Vandenbosch, R., Park, D. S., and Slack, R. S. (2012). Theretinoblastoma protein is essential for survival of postmitotic neurons. J. Neurosci. 32, 14809-14814. doi: 10.1523/JNEUROSCI.191212.2012

Archer, F. R., Doherty, P., Collins, D., and Bolsover, S. R. (1999). CAMs and FGF cause a local submembrane calcium signal promoting axon outgrowth without a rise in bulk calcium concentration. Eur. J. Neurosci. 11, 3565-3573. doi: 10.1046/j.1460-9568.1999.00773.x

Arenas, E., and Persson, H. (1994). Neurotrophin-3 prevents the death of adult central noradrenergic neurons in vivo. Nature 367, 368-371. doi: $10.1038 / 367368 \mathrm{a} 0$

Arimura, N., and Kaibuchi, K. (2005). Key regulators in neuronal polarity. Neuron 48, 881-884. doi: 10.1016/j.neuron.2005.11.007

Baloh, R. H., Gorodinsky, A., Golden, J. P., Tansey, M. G., Keck, C. L., Popescu, N. C., et al. (1998a). GFR $\alpha 3$ is an orphan member of the GDNF/neurturin/persephin receptor family. Proc. Natl. Acad. Sci. U S A 95, 5801-5806. doi: 10.1073/pnas.95.10.5801

Baloh, R. H., Tansey, M. G., Lampe, P. A., Fahrner, T. J., Enomoto, H., Simburger, K. S., et al. (1998b). Artemin, a novel member of the GDNF ligand family, supports peripheral and central neurons and signals through the GFR $\alpha 3-R E T$ receptor complex. Neuron 21, 1291-1302. doi: 10.1016/s08966273(00)80649-2 
Barbin, G., Manthorpe, M., and Varon, S. (1984). Purification of the chick eye ciliary neuronotrophic factor. J. Neurochem. 43, 1468-1478. doi: 10.1111/j. 1471-4159.1984.tb05410.x

Bhat, R. V., Baraban, J. M., Johnson, R. C., Eipper, B. A., and Mains, R. E. (1994). High levels of expression of the tumor suppressor gene APC during development of the rat central nervous system. J. Neurosci. 14, 3059-3071. doi: 10.1523/jneurosci.14-05-03059.1994

Boldyreva, M. A., Bondar, I. V., Stafeev, I. S., Makarevich, P. I., Beloglazova, I. B., Zubkova, E. S., et al. (2018). Plasmid-based gene therapy with hepatocyte growth factor stimulates peripheral nerve regeneration after traumatic injury. Biomed. Pharmacother. 101, 682-690. doi: 10.1016/j.biopha.2018.02.138

Bordet, T., Schmalbruch, H., Pettmann, B., Hagege, A., Castelnau-Ptakhine, L., Kahn, A., et al. (1999). Adenoviral cardiotrophin-1 gene transfer protects pmn mice from progressive motor neuronopathy. J. Clin. Invest. 104, 1077-1085. doi: $10.1172 /$ jci6265

Bottaro, D. P., Rubin, J. S., Faletto, D. L., Chan, A. M., Kmiecik, T. E., Vande Woude, G. F., et al. (1991). Identification of the hepatocyte growth factor receptor as the c-met proto-oncogene product. Science 251, 802-804. doi: $10.1126 /$ science. 1846706

Boucher, T. J., Okuse, K., Bennett, D. L., Munson, J. B., Wood, J. N., and McMahon, S. B. (2000). Potent analgesic effects of GDNF in neuropathic pain states. Science 290, 124-127. doi: 10.1126/science.290.5489.124

Boyer, N. P., and Gupton, S. L. (2018). Revisiting Netrin-1: one who guides (axons). Front. Cell. Neurosci. 12:221. doi: 10.3389/fncel.2018.00221

Braun, S., Croizat, B., Lagrange, M. C., Warter, J. M., and Poindron, P. (1996). Neurotrophins increase motoneurons' ability to innervate skeletal muscle fibers in rat spinal cord-human muscle cocultures. J. Neurol. Sci. 136, 17-23. doi: 10.1016/0022-510x(95)00315-s

Briançon-Marjollet, A., Ghogha, A., Nawabi, H., Triki, I., Auziol, C., Fromont, S., et al. (2008). Trio mediates netrin-1-induced Racl activation in axon outgrowth and guidance. Mol. Cell. Biol. 28, 2314-2323. doi: 10.1128/MCB.00998-07

Broderick, D. K., Di, C., Parrett, T. J., Samuels, Y. R., Cummins, J. M., McLendon, R. E., et al. (2004). Mutations of PIK3CA in anaplastic oligodendrogliomas, high-grade astrocytomas and medulloblastomas. Cancer Res. 64, 5048-5050. doi: 10.1158/0008-5472.CAN-04-1170

Brunet, A., Datta, S. R., and Greenberg, M. E. (2001). Transcription-dependent and -independent control of neuronal survival by the PI3K-Akt signaling pathway. Curr. Opin. Neurobiol. 11, 297-305. doi: 10.1016/s0959-4388(00)00211-7

Brushart, T. M., Hoffman, P. N., Royall, R. M., Murinson, B. B., Witzel, C., and Gordon, T. (2002). Electrical stimulation promotes motoneuron regeneration without increasing its speed or conditioning the neuron. J. Neurosci. 22, 6631-6638. doi: 10.1523/jneurosci.22-15-06631.2002

Brussee, V., Cunningham, F. A., and Zochodne, D. W. (2004). Direct insulin signaling of neurons reverses diabetic neuropathy. Diabetes 53, 1824-1830. doi: $10.2337 /$ diabetes.53.7.1824

Burnett, M. G., and Zager, E. L. (2004). Pathophysiology of peripheral nerve injury: a brief review. Neurosurg. Focus 16:E1. doi: 10.3171/foc.2004.16.5.2

Carpenter, G., and Cohen, S. (1979). Epidermal growth factor. Annu. Rev. Biochem. 48, 193-216. doi: 10.1146/annurev.bi.48.070179.001205

Chan, C. C., Khodarahmi, K., Liu, J., Sutherland, D., Oschipok, L. W., Steeves, J. D., et al. (2005). Dose-dependent beneficial and detrimental effects of ROCK inhibitor Y27632 on axonal sprouting and functional recovery after rat spinal cord injury. Exp. Neurol. 196, 352-364. doi: 10.1016/j.expneurol.2005. 08.011

Chang, C., Adler, C. E., Krause, M., Clark, S. G., Gertler, F. B., TessierLavigne, M., et al. (2006). MIG-10/lamellipodin and AGE-1/PI3K promote axon guidance and outgrowth in response to slit and netrin. Curr. Biol. 16, 854-862. doi: 10.1016/j.cub.2006.03.083

Chao, M. V. (2003). Neurotrophins and their receptors: a convergence point for many signalling pathways. Nat. Rev. Neurosci. 4, 299-309. doi: $10.1038 / \mathrm{nrn} 1078$

Chen, C., Bai, G. C., Jin, H. L., Lei, K., and Li, K. X. (2018). Local injection of bone morphogenetic protein 7 promotes neuronal regeneration and motor function recovery after acute spinal cord injury. Neural Regen. Res. 13, 1054-1060. doi: 10.4103/1673-5374.233449

Chen, Z. Y., He, Z. Y., He, C., Lu, C. L., and Wu, X. F. (2000). Human glial cell-linederived neurotrophic factor: a structure-function analysis. Biochem. Biophys. Res. Commun. 268, 692-696. doi: 10.1006/bbrc.2000.2196
Chen, Y. Y., McDonald, D., Cheng, C., Magnowski, B., Durand, J., and Zochodne, D. W. (2005). Axon and Schwann cell partnership during nerve regrowth. J. Neuropathol. Exp. Neurol. 64, 613-622. doi: 10.1097/01.jnen. 0000171650.94341 .46

Chen, Z. L., Yu, W. M., and Strickland, S. (2007). Peripheral regeneration. Annu. Rev. Neurosci. 30, 209-233. doi: 10.1146/annurev.neuro.30. 051606.094337

Chen, Z. W., and Wang, M. S. (1995). Effects of nerve growth factor on crushed sciatic nerve regeneration in rats. Microsurgery 16, 547-551. doi: 10.1002/micr. 1920160808

Cheng, C., Webber, C. A., Wang, J., Xu, Y., Martinez, J. A., Liu, W. Q., et al. (2008). Activated RHOA and peripheral axon regeneration. Exp. Neurol. 212, 358-369. doi: 10.1016/j.expneurol.2008.04.023

Chevrel, G., Hohlfeld, R., and Sendtner, M. (2006). The role of neurotrophins in muscle under physiological and pathological conditions. Muscle Nerve 33, 462-476. doi: 10.1002/mus.20444

Cho, H. J., Kim, J. K., Park, H. C., Kim, J. K., Kim, D. S., Ha, S. O., et al. (1998). Changes in brain-derived neurotrophic factor immunoreactivity in rat dorsal root ganglia, spinal cord, and gracile nuclei following cut or crush injuries. Exp. Neurol. 154, 224-230. doi: 10.1006/exnr.1998.6936

Choi, J., Ko, J., Racz, B., Burette, A., Lee, J. R., Kim, S., et al. (2005). Regulation of dendritic spine morphogenesis by insulin receptor substrate 53 , a downstream effector of Racl and Cdc42 small GTPases. J. Neurosci. 25, 869-879. doi: 10.1523/JNEUROSCI.3212-04.2005

Chou, H. J., Lai, D. M., Huang, C. W., McLennan, I. S., Wang, H. D., and Wang, P. Y. (2013). BMP4 is a peripherally-derived factor for motor neurons and attenuates glutamate-induced excitotoxicity in vitro. PLoS One 8:e58441. doi: 10.1371/journal.pone.0058441

Christie, K. J., Krishnan, A., Martinez, J. A., Purdy, K., Singh, B., Eaton, S., et al. (2014). Enhancing adult nerve regeneration through the knockdown of retinoblastoma protein. Nat. Commun. 5:3670. doi: 10.1038/ncomms4670

Christie, K. J., Webber, C. A., Martinez, J. A., Singh, B., and Zochodne, D. W. (2010). PTEN inhibition to facilitate intrinsic regenerative outgrowth of adult peripheral axons. J. Neurosci. 30, 9306-9315. doi: 10.1523/JNEUROSCI.627109.2010

Cirulli, V., and Yebra, M. (2007). Netrins: beyond the brain. Nat. Rev. Mol. Cell Biol. 8, 296-306. doi: 10.1038/nrm2142

Clarke, A. R., Maandag, E. R., van Roon, M., van der Lugt, N. M., van der Valk, M., Hooper, M. L., et al. (1992). Requirement for a functional Rb-1 gene in murine development. Nature 359, 328-330. doi: 10.1038/359328a0

Clevers, H. (2006). Wnt/ $\beta$-catenin signaling in development and disease. Cell 127, 469-480. doi: 10.1016/j.cell.2006.10.018

Collins, M. J., Napoli, I., Ribeiro, S., Roberts, S., and Lloyd, A. C. (2012). Loss of Rb cooperates with Ras to drive oncogenic growth in mammalian cells. Curr. Biol. 22, 1765-1773. doi: 10.1016/j.cub.2012.07.040

Culmsee, C., Stumm, R. K., Schäfer, M. K., Weihe, E., and Krieglstein, J. (1999a). "Neuroprotection by drug-induced growth factors," in Pharmacology of Cerebral Ischemia 1998, ed. J. Krieglstein (Stuttgart, Germany: Medpharm Scientific), 333-348.

Culmsee, C., Stumm, R. K., Schäfer, M. K., Weihe, E., and Krieglstein, J. (1999b). Clenbuterol induces growth factor mRNA, activates astrocytes and protects rat brain tissue against ischemic damage. Eur. J. Pharmacol. 379, 33-45. doi: 10.1016/s0014-2999(99)00452-5

Curtis, R., Scherer, S. S., Somogyi, R., Adryan, K. M., Ip, N. Y., Zhu, Y., et al. (1994). Retrograde axonal transport of LIF is increased by peripheral nerve injury: correlation with increased LIF expression in distal nerve. Neuron 12 , 191-204. doi: 10.1016/0896-6273(94)90163-5

Curtis, R., Tonra, J. R., Stark, J. L., Adryan, K. M., Park, J. S., Cliffer, K. D., et al. (1998). Neuronal injury increases retrograde axonal transport of the neurotrophins to spinal sensory neurons and motor neurons via multiple receptor mechanisms. Mol. Cell. Neurosci. 12, 105-118. doi: 10.1006/mcne. 1998.0704

Davey, F., Hilton, M., and Davies, A. M. (2000). Cooperation between HGF and CNTF in promoting the survival and growth of sensory and parasympathetic neurons. Mol. Cell. Neurosci. 15, 79-87. doi: 10.1006/mcne.1999.0803

David, M. D., Yeramian, A., Duñach, M., Llovera, M., Cantí, C., de Herreros, A. G., et al. (2008). Signalling by neurotrophins and hepatocyte growth factor regulates axon morphogenesis by differential $\beta$-catenin phosphorylation. J. Cell Sci. 121, 2718-2730. doi: 10.1242/jcs.029660 
Deiner, M. S., and Sretavan, D. W. (1999). Altered midline axon pathways and ectopic neurons in the developing hypothalamus of netrin-1- and DCC-deficient mice. J. Neurosci. 19, 9900-9912. doi: 10.1523/JNEUROSCI.1922-09900.1999

De la Hoz, C. L., Cheng, C., Fernyhough, P., and Zochodne, D. W. (2017). A model of chronic diabetic polyneuropathy: benefits from intranasal insulin are modified by sex and RAGE deletion. Am. J. Physiol. Endocrinol. Metab. 312, E407-E419. doi: 10.1152/ajpendo.00444.2016

Deng, Y., Xu, Y., Liu, H., Peng, H., Tao, Q., Liu, H., et al. (2018). Electrical stimulation promotes regeneration and re-myelination of axons of injured facial nerve in rats. Neurol. Res. 40, 231-238. doi: 10.1080/01616412.2018. 1428390

Derby, A., Engleman, V. W., Frierdich, G. E., Neises, G., Rapp, S. R., and Roufa, D. G. (1993). Nerve growth factor facilitates regeneration across nerve gaps: morphological and behavioral studies in rat sciatic nerve. Exp. Neurol. 119, 176-191. doi: 10.1006/exnr.1993.1019

Devaskar, S. U., Giddings, S. J., Rajakumar, P. A., Carnaghi, L. R., Menon, R. K., and Zahm, D. S. (1994). Insulin gene expression and insulin synthesis in mammalian neuronal cells. J. Biol. Chem. 269, 8445-8454.

Di Cristofano, A., Kotsi, P., Peng, Y. F., Cordon-Cardo, C., Elkon, K. B., and Pandolfi, P. P. (1999). Impaired Fas response and autoimmunity in Pten ${ }^{+/-}$ mice. Science 285, 2122-2125. doi: 10.1126/science.285.5436.2122

DiStefano, P. S., and Curtis, R. (1994). Receptor mediated retrograde axonal transport of neurotrophic factors is increased after peripheral nerve injury. Prog. Brain Res. 103, 35-42. doi: 10.1016/s0079-6123(08)61124-3

Dreyfus, C. F. (1989). Effects of nerve growth factor on cholinergic brain neurons. Trends Pharmacol. Sci. 10, 145-149. doi: 10.1016/0165-6147(89)90166-1

Dubreuil, C. I., Winton, M. J., and McKerracher, L. (2003). Rho activation patterns after spinal cord injury and the role of activated Rho in apoptosis in the central nervous system. J. Cell Biol. 162, 233-243. doi: 10.1083/jcb.200 301080

Dun, X. P., and Parkinson, D. B. (2017). Role of netrin-1 signaling in nerve regeneration. Int. J. Mol. Sci. 18:E491. doi: 10.3390/ijms18030491

Duraikannu, A., Martinez, J. A., Chandrasekhar, A., and Zochodne, D. W. (2018). Expression and manipulation of the APC- $\beta$-catenin pathway during peripheral neuron regeneration. Sci. Rep. 8:13197. doi: 10.1038/s41598-018-31167-1

Ebendal, T., Bengtsson, H., and Söderström, S. (1998). Bone morphogenetic proteins and their receptors: potential functions in the brain. J. Neurosci. Res. 51, 139-146. doi: 10.1002/(sici)1097-4547(19980115)51:2<139::aid-jnr2>3.0. co;2-e

Eggers, R., Hendriks, W. T., Tannemaat, M. R., van Heerikhuize, J. J., Pool, C. W., Carlstedt, T. P., et al. (2008). Neuroregenerative effects of lentiviral vectormediated GDNF expression in reimplanted ventral roots. Mol. Cell Neurosci. 39, 105-117. doi: 10.1016/j.mcn.2008.05.018

Ekström, P. A., Kerekes, N., and Hökfelt, T. (2000). Leukemia inhibitory factor null mice: unhampered in vitro outgrowth of sensory axons but reduced stimulatory potential by nerve segments. Neurosci. Lett. 281, 107-110. doi: 10.1016/s03043940(00)00816-8

Elul, T. M., Kimes, N. E., Kohwi, M., and Reichardt, L. F. (2003). N- and C-Terminal domains of $\beta$-catenin, respectively, are required to initiate and shape axon arbors of retinal ganglion cells in vivo. J. Neurosci. 23, 6567-6575. doi: 10.1523/JNEUROSCI.23-16-06567.2003

English, A. W., Schwartz, G., Meador, W., Sabatier, M. J., and Mulligan, A. (2007). Electrical stimulation promotes peripheral axon regeneration by enhanced neuronal neurotrophin signaling. Dev. Neurobiol. 67, 158-172. doi: 10.1002/dneu.20339

Enokido, Y., de Sauvage, F., Hongo, J. A., Ninkina, N., Rosenthal, A., Buchman, V. L., et al. (1998). GFR $\alpha-4$ and the tyrosine kinase Ret form a functional receptor complex for persephin. Curr. Biol. 8, 1019-1022. doi: 10.1016/s0960-9822(07)00422-8

Ferguson, K. L., McClellan, K. A., Vanderluit, J. L., McIntosh, W. C., Schuurmans, C., Polleux, F., et al. (2005). A cell-autonomous requirement for the cell cycle regulatory protein, $\mathrm{Rb}$, in neuronal migration. EMBO J. 24, 4381-4391. doi: 10.1038/sj.emboj.7600887

Ferguson, K. L., Vanderluit, J. L., Hébert, J. M., McIntosh, W. C., Tibbo, E., MacLaurin, J. G., et al. (2002). Telencephalon-specific Rb knockouts reveal enhanced neurogenesis, survival and abnormal corticaldevelopment. EMBO J. 21, 3337-3346. doi: 10.1093/emboj/cdf338
Fernyhough, P., Mill, J. F., Roberts, J. L., and Ishii, D. N. (1989). Stabilization of tubulin mRNAs by insulin and insulin-like growth factor I during neurite formation. Mol. Brain Res. 6, 109-120. doi: 10.1016/0169-328x(89) 90044-2

Fernyhough, P., Willars, G. B., Lindsay, R. M., and Tomlinson, D. R. (1993). Insulin and insulin-like growth factor I enhance regeneration in cultured adult rat sensory neurones. Brain Res. 607, 117-124. doi: 10.1016/00068993(93)91496-f

Foster, E., Robertson, B., and Fried, K. (1994). trkB-like immunoreactivity in rat dorsal root ganglia following sciatic nerve injury. Brain Res. 659, 267-271. doi: 10.1016/0006-8993(94)90891-5

Fu, P. C., Tang, R. H., Wan, Y., Xie, M. J., Wang, W., Luo, X., et al. (2016). ROCK inhibition with fasudil promotes early functional recovery of spinal cord injury in rats by enhancing microglia phagocytosis. J. Huazhong Univ. Sci. Technol. Med. Sci. 36, 31-36. doi: 10.1007/s11596-016-1537-3

Fujimoto, E., Mizoguchi, A., Hanada, K., Yajima, M., and Ide, C. (1997). Basic fibroblast growth factor promotes extension of regenerating axons of peripheral nerve. In vivo experiments using a Schwann cell basal lamina tube model. J. Neurocytol. 26, 511-528. doi: 10.1023/A:1015410 023132

Fukuoka, T., Kondo, E., Dai, Y., Hashimoto, N., and Noguchi, K. (2001). Brainderived neurotrophic factor increases in the uninjured dorsal root ganglion neurons in selective spinal nerve ligation model. J. Neurosci. 21, 4891-4900. doi: 10.1523/JNEUROSCI.21-13-04891.2001

Gatzinsky, K. P., Holtmann, B., Daraie, B., Berthold, C. H., and Sendtner, M. (2003). Early onset of degenerative changes at nodes of Ranvier in $\alpha$-motor axons of Cntf null $\left(^{-/}\right)$mutant mice. Glia. 42, 340-349. doi: 10.1002/glia. 10221

Geng, S. J., Liao, F. F., Dang, W. H., Ding, X., Liu, X. D., Cai, J., et al. (2010), Contribution of the spinal cord BDNF to the development of neuropathic pain by activation of the NR2B-containing NMDA receptors in rats with spinal nerve ligation. Exp. Neurol. 222, 256-266. doi: 10.1016/j.expneurol.2010. 01.003

Geoffroy, C. G., Hilton, B. J., Tetzlaff, W., and Zheng, B. (2016). Evidence for an age-dependent decline in axon regeneration in the adult mammalian central nervous system. Cell Rep. 15, 238-246. doi: 10.1016/j.celrep.2016. 03.028

Geremia, N. M., Gordon, T., Brushart, T. M., Al-Majed, A. A., and Verge, V. M. (2007). Electrical stimulation promotes sensory neuron regeneration and growth-associated gene expression. Exp. Neurol. 205, 347-359. doi: 10.1016/j. expneurol.2007.01.040

Giacinti, C., and Giordano, A. (2006). RB and cell cycle progression. Oncogene 25, 5220-5227. doi: 10.1038/sj.onc. 1209615

Golden, J. P., DeMaro, J. A., Osborne, P. A., Milbrandt, J., and Johnson, E. M. Jr. (1999). Expression of neurturin, GDNF, and GDNF family-receptor mRNA in the developing and mature mouse. Exp. Neurol. 158, 504-528. doi: 10.1006/exnr.1999.7127

Gordon, T., Amirjani, N., Edwards, D. C., and Chan, K. M. (2010). Brief post-surgical electrical stimulation accelerates axon regeneration and muscle reinnervation without affecting the functional measures in carpal tunnel syndrome patients. Exp. Neurol. 223, 192-202. doi: 10.1016/j.expneurol.2009. 09.020

Gordon, T., Brushart, T. M., Amirjani, N., and Chan, K. M. (2007). The potential of electrical stimulation to promote functional recovery after peripheral nerve injury-comparisons between rats and humans. Acta Neurochir. 100, 3-11. doi: 10.1007/978-3-211-72958-8_1

Gordon, T., Brushart, T. M., and Chan, K. M. (2008). Augmenting nerve regeneration with electrical stimulation. Neurol. Res. 30, 1012-1022. doi: $10.1179 / 174313208 \times 362488$

Gordon, T., Chan, K. M., Sulaiman, O. A., Udina, E., Amirjani, N., and Brushart, T. M. (2009). Accelerating axon growth to overcome limitations in functional recovery after peripheral nerve injury. Neurosurgery 65, A132-A144. doi: 10.1227/01.neu.0000335650.09473.d3

Gospodarowicz, D. (1979). Fibroblast and epidermal growth factors: their uses in vivo and in vitro in studies on cell functions and cell transplantation. Mol. Cell. Biochem. 25, 79-110. doi: 10.1007/bf00228991

Gospodarowicz, D., Cheng, J., Lui, G. M., Baird, A., and Böhlent, P. (1984). Isolation of brain fibroblast growth factor by heparin-Sepharose affinity 
chromatography: identity with pituitary fibroblast growth factor. Proc. Natl. Acad. Sci. U S A 81, 6963-6967. doi: 10.1073/pnas.81.22.6963

Govind, S., Kozma, R., Monfries, C., Lim, L., and Ahmed, S. (2001). Cdc42Hs facilitates cytoskeletal reorganization and neurite outgrowth by localizing the $58-\mathrm{kD}$ insulin receptor substrate to filamentous actin. J. Cell Biol. 152, 579-594. doi: $10.1083 /$ jcb.152.3.579

Gowen, L. C., Johnson, B. L., Latour, A. M., Sulik, K. K., and Koller, B. H. (1996). Brcal deficiency results in early embryonic lethality characterized by neuroepithelial abnormalities. Nat. Genet. 12, 191-194. doi: 10.1038/ ng0296-191

Grigoryan, T., Stein, S., Qi, J., Wende, H., Garratt, A. N., Nave, K. A., et al. (2013). Wnt/Rspondin/ $\beta$-catenin signals control axonal sorting and lineage progression in Schwann cell development. Proc. Natl. Acad. Sci. U S A 110, 18174-18179. doi: 10.1073/pnas.1310490110

Grothe, C., Meisinger, C., and Claus, P. (2001). In vivo expression and localization of the fibroblast growth factor system in the intact and lesioned rat peripheral nerve and spinal ganglia. J. Comp. Neurol. 434, 342-357. doi: 10.1002/cne.1181

Grothe, C., and Nikkhah, G. (2001). The role of basic fibroblast growth factor in peripheral nerve regeneration. Anat. Embryol. 204, 171-177. doi: $10.1007 / \mathrm{s} 004290100205$

Guha, U., Gomes, W. A., Samanta, J., Gupta, M., Rice, F. L., and Kessler, J. A. (2004). Target-derived BMP signaling limits sensory neuron number and the extent of peripheral innervation in vivo. Development 131, 1175-1186. doi: $10.1242 /$ dev.01013

Guo, G., Kan, M., Martinez, J. A., and Zochodne, D. W. (2011). Local insulin and the rapid regrowth of diabetic epidermal axons. Neurobiol. Dis. 43, 414-421. doi: 10.1016/j.nbd.2011.04.012

Guo, G., Singh, V., and Zochodne, D. W. (2014). Growth and turning properties of adult glial cell-derived neurotrophic factor coreceptor $\alpha 1$ nonpeptidergic sensory neurons. J. Neuropathol. Exp. Neurol. 73, 820-836. doi: 10.1097/NEN. 0000000000000101

Haastert, T. K., Schmitte, R., Korte, N., Klode, D., Ratzka, A., and Grothe, C. (2011). Electrical stimulation accelerates axonal and functional peripheral nerve regeneration across long gaps. J. Neurotrauma. 28, 661-674. doi: 10.1089/neu.2010.1637

Hammarberg, H., Piehl, F., Risling, M., and Cullheim, S. (2000). Differential regulation of trophic factor receptor mRNAs in spinal motoneurons after sciatic nerve transection and ventral root avulsion in the rat. J. Comp. Neurol. 426, 587-601. doi: 10.1002/1096-9861(20001030)426:4<587::aid-cne7>3.0. $\mathrm{co} ; 2-\mathrm{r}$

Hanson, C. A., and Miller, J. R. (2005). Non-traditional roles for the adenomatous polyposis coli (APC) tumor suppressor protein. Gene 361, 1-12. doi: 10.1016/j. gene.2005.07.024

Hatten, M. E., Lynch, M., Rydel, R. E., Sanchez, J., Joseph-Silverstein, J., Moscatelli, D., et al. (1988). in vitro neurite extension by granule neurons is dependent upon astroglial-derived fibroblast growth factor. Dev. Biol. 125, 280-289. doi: 10.1016/0012-1606(88)90211-4

Heinrich, P. C., Behrmann, I., Müller-Newen, G., Schaper, F., and Graeve, L. (1998). Interleukin-6-type cytokine signalling through the gp130/Jak/STAT pathway. Biochem. J. 334, 297-314. doi: 10.1042/bj3340297

Helfand, S. L., Smith, G. A., and Wessells, N. K. (1976). Survival and development in culture of dissociated parasympathetic neurons from ciliary ganglia. Dev. Biol. 50, 541-547. doi: 10.1016/0012-1606(76)90174-3

Hempstead, B. L., Martin-Zanca, D., Kaplan, D. R., Parada, L. F., and Chao, M. V. (1991). High-affinity NGF binding requires coexpression of the trk proto-oncogene and the low-affinity NGF receptor. Nature 350, 678-683. doi: $10.1038 / 350678 \mathrm{a} 0$

Henderson, C. E., Camu, W., Mettling, C., Gouin, A., Poulsen, K., Karihaloo, M., et al. (1993). Neurotrophins promote motor neuron survival and are present in embryonic limb bud. Nature 363, 266-270. doi: 10.1038/363266a0

Heuckeroth, R. O., Enomoto, H., Grider, J. R., Golden, J. P., Hanke, J. A., Jackman, A., et al. (1999). Gene targeting reveals a critical role for neurturin in the development and maintenance of enteric, sensory, and parasympathetic neurons. Neuron 22, 253-263. doi: 10.1016/s0896-6273(00) 81087-9

Heumann, R., Korsching, S., Bandtlow, C., and Thoenen, H. (1987). Changes of nerve growth factor synthesis in nonneuronal cells in response to sciatic nerve transection. J. Cell Biol. 104, 1623-1631. doi: 10.1083/jcb.104.6.1623
Hiraga, A., Kuwabara, S., Doya, H., Kanai, K., Fujitani, M., Taniguchi, J., et al. (2006). Rho-kinase inhibition enhances axonal regeneration after peripheral nerve injury. J. Peripher. Nerv. Syst. 11, 217-224. doi: 10.1111/j.1529-8027.2006. 00091.x

Hoke, A., Cheng, C., and Zochodne, D. W. (2000). Expression of glial cell line-derived neurotrophic factor family of growth factors in peripheral nerve injury in rats. Neuroreport 11, 1651-1654. doi: 10.1097/00001756-20000605000011

Hoke, A., Gordon, T., Zochodne, D. W., and Sulaiman, O. A. (2002). A decline in glial cell-line-derived neurotrophic factor expression is associated with impaired regeneration after long-term Schwann cell denervation. Exp. Neurol. 173, 77-85. doi: 10.1006/exnr.2001.7826

Hoke, A., Sun, H., Gordon, T., and Zochodne, D. W. (2001). Do denervated peripheral nerve trunks become ischemic? The impact of chronic denervation on vasa nervorum. Exp. Neurol. 172, 398-406. doi: 10.1006/exnr. 2001.7808

Horger, B. A., Nishimura, M. C., Armanini, M. P., Wang, L. C., Poulsen, K. T., Rosenblad, C., et al. (1998). Neurturin exerts potent actions on survival and function of midbrain dopaminergic neurons. J. Neurosci. 18, 4929-4937. doi: 10.1523/JNEUROSCI.18-13-04929.1998

Horie, H., Bando, Y., Chi, H., and Takenaka, T. (1991). NGF enhances neurite regeneration from nerve-transected terminals of young adult and aged mouse dorsal root ganglia in vitro. Neurosci. Lett. 121, 125-128. doi: 10.1016/03043940(91)90665-g

Hoybergs, Y. M., and Meert, T. F. (2007). The effect of low-dose insulin on mechanical sensitivity and allodynia in type I diabetes neuropathy. Neurosci. Lett. 417, 149-154. doi: 10.1016/j.neulet.2007.02.087

Hu, J., and Selzer, M. E. (2017). RhoA as a target to promote neuronal survival and axon regeneration. Neural Regen Res. 12, 525-528. doi: 10.4103/1673-5374. 205080

Huang, E. J., and Reichardt, L. F. (2001). Neurotrophins: roles in neuronal development and function. Annu. Rev. Neurosci. 24, 677-736. doi: 10.1146/annurev.neuro.24.1.677

Huang, E. J., and Reichardt, L. F. (2003). Trk receptors: roles in neuronal signal transduction. Annu. Rev. Biochem. 72, 609-642. doi: 10.1146/annurev.biochem. 72.121801 .161629

Huang, J., Ye, Z., Hu, X., Lu, L., and Luo, Z. (2010). Electrical stimulation induces calcium-dependent release of NGF from cultured Schwann cells. Glia 58, 622-631. doi: 10.1002/glia.20951

Huerta, J. J., Diaz-Trelles, R., Naves, F. J., Llamosas, M. M., Del Valle, M. E., and Vega, J. A. (1996). Epidermal growth factor receptor in adult human dorsal root ganglia. Anat. Embryol. 194, 253-257. doi: 10.1007/bf00187136

Hyman, C., Juhasz, M., Jackson, C., Wright, P., Ip, N. Y., and Lindsay, R. M. (1994). Overlapping and distinct actions of the neurotrophins BDNF, NT-3, and NT $-4 / 5$ on cultured dopaminergic and GABAergic neurons of the ventral mesencephalon. J. Neurosci. 14, 335-347. doi: 10.1523/JNEUROSCI.14-0100335.1994

Ichikawa, H., Itota, T., Nishitani, Y., Torii, Y., Inoue, K., and Sugimoto, T. (2000). Osteopontin-immunoreactive primary sensory neurons in the rat spinal and trigeminal nervous systems. Brain Res. 863, 276-281. doi: 10.1016/s00068993(00)02126-0

Ide, C. (1996). Peripheral nerve regeneration. Neurosci. Res. 25, 101-121. doi: 10.1016/0168-0102(96)01042-5

Ikeda-Miyagawa, Y., Kobayashi, K., Yamanaka, H., Okubo, M., Wang, S. Dai, Y., et al. (2015). Peripherally increased artemin is a key regulator of TRPA1/V1 expression in primary afferent neurons. Mol. Pain 11:8. doi: 10.1186/s12990-015-0004-7

Imamura, T., Tokita, Y., and Mitsui, Y. (1988). Purification of basic FGF receptors from rat brain. Biochem. Biophys. Res. Commun. 55, 583-590. doi: $10.1016 / \mathrm{s} 0006-291 \mathrm{x}(88) 80534-5$

Ito, Y., Yamamoto, M., Li, M., Mitsuma, N., Tanaka, F., Doyu, M., et al. (2000). Temporal expression of mRNAs for neuropoietic cytokines, interleukin-11 (IL11), oncostatin M (OSM), cardiotrophin-1 (CT-1) and their receptors (IL$11 \mathrm{R} \alpha$ and OSMR $\beta$ ) in peripheral nerve injury. Neurochem. Res. 25, 1113-1118. doi: 10.1023/A:1007674113440

Jacks, T., Fazeli, A., Schmitt, E. M., Bronson, R. T., Goodell, M. A., and Weinberg, R. A. (1992). Effects of an Rb mutation in the mouse. Nature 359, 295-300. doi: $10.1038 / 359295 a 0$ 
Jakobiec, F. A., Tso, M. O., Zimmerman, L. E., and Danis, P. (1977). Retinoblastoma and intracranial malignancy. Cancer 39, 2048-2058. doi: 10. 1002/1097-0142(197705)39:5<2048::aid-cncr2820390522>3.0.co;2-9

Jander, S., Bussini, S., Neuen-Jacob, E., Bosse, F., Menge, T., Müller, H. W., et al. (2002). Osteopontin: a novel axon-regulated Schwann cell gene. J. Neurosci. Res. 67, 156-166. doi: 10.1002/jnr.10099

Jeong, D. G., Park, W. K., and Park, S. (2008). Artemin activates axonal growth via SFK and ERK-dependent signalling pathways in mature dorsal root ganglia neurons. Cell Biochem. Funct. 26, 210-220. doi: 10.1002/cbf.1436

Ji, R. R., Zhang, Q., Zhang, X., Piehl, F., Reilly, T., Pettersson, R. F., et al. (1995). Prominent expression of bFGF in dorsal root ganglia after axotomy. Eur. J. Neurosci. 7, 2458-2468. doi: 10.1111/j.1460-9568.1995.tb01044.x

Jiang, H., Guo, W., Liang, X., and Rao, Y. (2005). Both the establishment and the maintenance of neuronal polarity require active mechanisms: critical roles of GSK-3 $\beta$ and its upstream regulators. Cell 120, 123-135. doi: 10.1016/s00928674(04)01258-9

Jiang, Y., Min-tsai, L., and Gershon, M. D. (2003). Netrins and DCC in the guidance of migrating neural crest-derived cells in the developing bowel and pancreas. Dev. Biol. 258, 364-384. doi: 10.1016/s0012-1606(03) 00136-2

Joshi, A. R., Bobylev, I., Zhang, G., Sheikh, K. A., and Lehmann, H. C. (2015). Inhibition of Rho-kinase differentially affects axon regeneration of peripheral motor and sensory nerves. Exp. Neurol. 263, 28-38. doi: 10.1016/j.expneurol. 2014.09.012

Jungnickel, J., Haase, K., Konitzer, J., Timmer, M., and Grothe, C. (2006). Faster nerve regeneration after sciatic nerve injury in mice over-expressing basic fibroblast growth factor. J. Neurobiol. 66, 940-948. doi: 10.1002/neu. 20265

Kaplan, D. R., and Miller, F. D. (1997). Signal transduction by the neurotrophin receptors. Curr. Opin. Cell Biol. 9, 213-221. doi: 10.1016/S0955-0674(97)8 0065-8

Kashiba, H., and Senba, E. (1999). Up and down-regulation of BDNF mRNA in distinct subgroups of rat sensory neurons after axotomy. Neuro. Report. 10, 3561-3565. doi: 10.1097/00001756-199911260-00018

Kath, C., Goni-Oliver, P., Müller, R., Schultz, C., Haucke, V., Eickholt, B., et al. (2018). PTEN suppresses axon outgrowth by down-regulating the level of detyrosinated microtubules. PLoS One 13:e0193257. doi: 10.1371/journal.pone. 0193257

Kato, N., Nemoto, K., Nakanishi, K., Morishita, R., Kaneda, Y., Uenoyama, M., et al. (2005). Nonviral HVJ (hemagglutinating virus of Japan) liposomemediated retrograde gene transfer of human hepatocyte growth factor into rat nervous system promotes functional and histological recovery of the crushed nerve. Neurosci Res. 52, 299-310. doi: 10.1016/j.neures.2005.04.004

Katoh-Semba, R., Kaisho, Y., Shintani, A., Nagahama, M., and Kato, K. (1996). Tissue distribution and immunocytochemical localization of neurotrophin-3 in the brain and peripheral tissues of rats. J. Neurochem. 66, 330-337. doi: 10.1046/j.1471-4159.1996.66010330.x

Keefe, K. M., Sheikh, I. S., and Smith, G. M. (2017). Targeting neurotrophins to specific populations of neurons: NGF, BDNF and NT-3 and their relevance for treatment of spinal cord injury. Int. J. Mol. Sci. 18:E548. doi: 10.3390/ijms 18030548

Keino-Masu, K., Masu, M., Hinck, L., Leonardo, E. D., Chan, S. S., Culotti, J. G., et al. (1996). Deleted in colorectal cancer (DCC) encodes a netrin receptor. Cell 87, 175-185. doi: 10.1016/s0092-8674(00)81336-7

Kemp, S. W., Walsh, S. K., Zochodne, D. W., and Midha, R. (2007). A novel method for establishing daily in vivo concentration gradients of soluble nerve growth factor (NGF). J. Neurosci. Methods 165, 83-88. doi: 10.1016/j.jneumeth. 2007.05.032

Kennedy, T. E., Serafini, T., de la Torre, J. R., and Tessier-Lavigne, M. (1994). Netrins are diffusible chemotropic factors for commissural axons in the embryonic spinal cord. Cell 78, 425-435. doi: 10.1016/0092-8674(94)90421-9

Kim, M. S., El-Fiqi, A., Kim, J. W., Ahn, H. S., Kim, H., Son, Y. J., et al. (2016). Nanotherapeutics of PTEN inhibitor with mesoporous silica nanocarrier effective for axonal outgrowth of adult neurons. ACS Appl. Mater. Interfaces 8, 18741-18753. doi: 10.1021/acsami.6b06889

Kimelman, D., and Xu, W. (2006). $\beta$-catenin destruction complex: insights andquestions from a structural perspective. Oncogene 25, 7482-7491. doi: 10.1038/sj.onc. 1210055
Ko, K. R., Lee, J., Lee, D., Nho, B., and Kim, S. (2018). Hepatocyte growth factor (HGF) promotes peripheral nerve regeneration by activating repair schwann cells. Sci. Rep. 8:8316. doi: 10.1038/s41598-018-26704-x

Kobayashi, H., Yokoyama, M., Matsuoka, Y., Omori, M., Itano, Y., Kaku, R., et al. (2008). Expression changes of multiple brain-derived neurotrophic factor transcripts in selective spinal nerve ligation model and complete Freund's adjuvant model. Brain Res. 1206, 13-19. doi: 10.1016/j.brainres.2007.12.004

Korhonen, L., Brännvall, K., Skoglösa, Y., and Lindholm, D. (2003). Tumor suppressor gene BRCA-1 is expressed by embryonic and adult neural stem cells and involved in cell proliferation. J. Neurosci. Res. 71, 769-776. doi: 10.1002/jnr. 10546

Kotzbauer, P. T., Lampe, P. A., Heuckeroth, R. O., Golden, J. P., Creedon, D. J., Johnson, E. M. Jr., et al. (1996). Neurturin, a relative of glial-cell-line-derived neurotrophic factor. Nature 384, 467-470. doi: 10.1038/384467a0

Krishnan, A., Bhavanam, S., and Zochodne, D. (2018a). An intimate role for adult dorsal root ganglia resident cycling cells in the generation of local macrophages and satellite glial cells. J. Neuropathol. Exp. Neurol. 77, 929-941. doi: 10.1093/jnen/nly072

Krishnan, A., Purdy, K., Chandrasekhar, A., Martinez, J., Cheng, C., and Zochodne, D. W. (2018b). A BRCA1-dependent DNA damage response in the regenerating adult peripheral nerve milieu. Mol. Neurobiol. 55, 4051-4067. doi: 10.1007/s12035-017-0574-7

Kume, T., Nishikawa, H., Tomioka, H., Katsuki, H., Akaike, A., Kaneko, S., et al. (2000). p75-mediated neuroprotection by NGF against glutamate cytotoxicity in cortical cultures. Brain Res. 852, 279-289. doi: 10.1016/s00068993(99)02226-x

Kurek, J. B., Austin, L., Cheema, S. S., Bartlett, P. F., and Murphy, M. (1996). Upregulation of leukaemia inhibitory factor and interleukin-6 in transected sciatic nerve and muscle following denervation. Neuromuscul. Disord. 6, 105-114. doi: 10.1016/0960-8966(95)00029-1

Kurek, J. B., Bower, J. J., Romanella, M., Koentgen, F., Murphy, M., and Austin, L. (1997). The role of leukemia inhibitory factor in skeletal muscle regeneration. Muscle Nerve 20, 815-822. doi: 10.1002/(sici)10974598(199707)20:7<815::aid-mus5 > 3.0.co;2-a

Kwon, C. H., Luikart, B. W., Powell, C. M., Zhou, J., Matheny, S. A., Zhang, W., et al. (2006). Pten regulates neuronal arborization and social interaction in mice. Neuron 50, 377-388. doi: 10.1016/j.neuron.2006.03.023

Langeslag, M., Constantin, C. E., Andratsch, M., Quarta, S., Mair, N., and Kress, M. (2011). Oncostatin M induces heat hypersensitivity by gp130-dependent sensitization of TRPV1 in sensory neurons. Mol. Pain 7:102. doi: 10.1186/17448069-7-102

Lee, E. Y., Chang, C. Y., Hu, N., Wang, Y. C., Lai, C. C., Herrup, K., et al. (1992). Mice deficient for $\mathrm{Rb}$ are nonviable and show defects in neurogenesis and haematopoiesis. Nature 359, 288-294. doi: 10.1038/359288a0

Lee, M. Y., Choi, J. S., Lim, S. W., Cha, J. H., Chun, M. H., and Chung, J. W. (2001). Expression of osteopontin mRNA in developing rat brainstem and cerebellum. Cell Tissue Res. 306, 179-185. doi: 10.1007/s004410100456

Lee, S. H., Jin, W. P., Seo, N. R., Pang, K. M., Kim, B., Kim, S. M., et al. (2017). Recombinant human fibroblast growth factor-2 promotes nerve regeneration and functional recovery after mental nerve crush injury. Neural Regen. Res. 12, 629-636. doi: 10.4103/1673-5374.205104

Lehmann, M., Fournier, A., Selles-Navarro, I., Dergham, P., Sebok, A., Leclerc, N., et al. (1999). Inactivation of Rho signaling pathway promotes CNS axon regeneration. J. Neurosci. 19, 7537-7547. doi: 10.1523/JNEUROSCI.19-1707537.1999

Leitner, M. L., Molliver, D. C., Osborne, P. A., Vejsada, R., Golden, J. P., Lampe, P. A., et al. (1999). Analysis of the retrograde transport of glial cell line-derived neurotrophic factor (GDNF), neurturin, and persephin suggests that in vivo signaling for the GDNF family is GFR $\alpha$ coreceptor-specific. J. Neurosci. 19, 9322-9331. doi: 10.1523/JNEUROSCI.19-21-09322.1999

Leonardo, E. D., Hinck, L., Masu, M., Keino-Masu, K., Ackerman, S. L., and Tessier-Lavigne, M. (1997). Vertebrate homologues of C. elegans UNC-5 are candidate netrin receptors. Nature 386, 833-838. doi: 10.1038/386833a0

Levi-Montalcini, R. (1987). The nerve growth factor: thirty-five years later. $E M B O$ J. 6, 1145-1154. doi: 10.1002/j.1460-2075.1987.tb02347.x

Levi-Montalcini, R. (1950). The origin and development of the visceral system in the spinal cord or chick embryo. Dev. Biol. 86, 253-284. doi: 10.1002/jmor. 1050860203 
Li, D. M., and Sun, H. (1997). TEP1, encoded by a candidate tumor suppressor locus, is a novel protein tyrosine phosphatase regulated by transforming growth factor $\beta$. Cancer Res. 57, 2124-2129.

Li, G. D., Wo, Y., Zhong, M. F., Zhang, F. X., Bao, L., Lu, Y. J., et al. (2002). Expression of fibroblast growth factors in rat dorsal root ganglion neurons and regulation after peripheral nerve injury. Neuroreport 13, 1903-1907. doi: 10.1097/00001756-200210280-00014

Liaw, L., Skinner, M. P., Raines, E. W., Ross, R., Cheresh, D. A., Schwartz, S. M., et al. (1995). The adhesive and migratory effects of osteopontin are mediated via distinct cell surface integrins. Role of $\alpha \mathrm{v} \beta 3$ in smooth muscle cell migration to osteopontin in vitro. J. Clin. Invest. 95, 713-724. doi: 10.1172/jci1 17718

Lin, L. F., Doherty, D. H., Lile, J. D., Bektesh, S., and Collins, F. (1993). GDNF: a glial cell line-derived neurotrophic factor for midbrain dopaminergic neurons. Science 260, 1130-1132. doi: 10.1126/science.8493557

Liu, Y., Kelamangalath, L., Kim, H., Han, S. B., Tang, X., Zhai, J., et al. (2016). NT3 promotes proprioceptive axon regeneration when combined with activation of the mTor intrinsic growth pathway but not with reduction of myelin extrinsic inhibitors. Exp. Neurol. 283, 73-84. doi: 10.1016/j.expneurol.2016. 05.021

Lu, M. C., Ho, C. Y., Hsu, S. F., Lee, H. C., Lin, J. H., Yao, C. H., et al. (2008). Effects of electrical stimulation at different frequencies on regeneration of transected peripheral nerve. Neurorehabil. Neural Repair 22, 367-373. doi: $10.1177 / 1545968307313507$

MacPherson, D., Sage, J., Kim, T., Ho, D., McLaughlin, M. E., and Jacks, T. (2004). Cell typespecific effects of $\mathrm{Rb}$ deletion in the murine retina. Genes Dev. 18, 1681-1694. doi: 10.1101/gad.1203304

Maina, F., Hilton, M. C., Ponzetto, C., Davies, A. M., and Klein, R. (1997). Met receptor signaling is required for sensory nerve development and HGF promotes axonal growth and survival of sensory neurons. Genes Dev. 11, 3341-3350. doi: 10.1101/gad.11.24.3341

Maklad, A., Nicolai, J. R., Bichsel, K. J., Evenson, J. E., Lee, T. C., Threadgill, D. W., et al. (2009). The EGFR is required for proper innervation to the skin. J. Invest. Dermatol. 129, 690-698. doi: 10.1038/jid.2008.281

Manitt, C., Nikolakopoulou, A. M., Almario, D. R., Nguyen, S. A., and CohenCory, S. (2009). Netrin participates in the development of retinotectal synaptic connectivity by modulating axon arborization and synapse formation in the developing brain. J. Neurosci. 29, 11065-11077. doi: 10.1523/JNEUROSCI. 0947-09.2009

Manthorpe, M., Skaper, S. D., Williams, L. R., and Varon, S. (1986). Purification of adult rat sciatic nerve ciliary neuronotrophic factor. Brain Res. 367, 282-286. doi: 10.1016/0006-8993(86)91603-3

Marcus, D. M., Brooks, S. E., Leff, G., McCormick, R., Thompson, T., Anfinson, S., et al. (1998). Trilateral retinoblastoma: insights into histogenesis and management. Surv. Ophthalmol. 43, 59-70. doi: 10.1016/S0039-6257(98) 00019-8

Masuda, T., Watanabe, K., Sakuma, C., Ikenaka, K., Ono, K., and Yaginuma, H. (2008). Netrin-1 acts as a repulsive guidance cue for sensory axonal projections toward the spinal cord. J. Neurosci. 28, 10380-10385. doi: 10.1523/JNEUROSCI.1926-08.2008

McClellan, K. A., Ruzhynsky, V. A., Douda, D. N., Vanderluit, J. L., Ferguson, K. L., Chen, D., et al. (2007). Unique requirement for Rb/E2F3 in neuronal migration: evidence for cell cycle-independent functions. Mol. Cell. Biol. 27, 4825-4843. doi: 10.1128/mcb.02100-06

McDonald, D., Cheng, C., Chen, Y., and Zochodne, D. (2006). Early events of peripheral nerve regeneration. Neuron Glia Biol. 2, 139-147. doi: 10.1017/S1740925X05000347

McKay Hart, A., Brannstrom, T., Wiberg, M., and Terenghi, G. (2002). Primary sensory neurons and satellite cells after peripheral axotomy in the adult rat: timecourse of cell death and elimination. Exp. Brain Res. 142, 308-318. doi: 10.1007/s00221-001-0929-0

McLean, N. A., Popescu, B. F., Gordon, T., Zochodne, D. W., and Verge, V. M. (2014). Delayed nerve stimulation promotes axon-protective neurofilament phosphorylation, accelerates immune cell clearance and enhances remyelination in vivo in focally demyelinated nerves. PLoS One 9:e110174. doi: 10.1371/journal.pone.0110174

McNay, E. C., Ong, C. T., McCrimmon, R. J., Cresswell, J., Bogan, J. S., and Sherwin, R. S. (2010). Hippocampal memory processes are modulated by insulin and high-fat-induced insulin resistance. Neurobiol. Learn. Mem. 93, 546-553. doi: 10.1016/j.nlm.2010.02.002

Mehlen, P., Delloye-Bourgeois, C., and Chedotal, A. (2011). Novel roles for Slits and netrins: axon guidance cues as anticancer targets? Nat. Rev. Cancer 11, 188-197. doi: 10.1038/nrc3005

Mehlen, P., and Mazelin, L. (2003). The dependence receptors DCC and UNC5H as a link between neuronal guidance and survival. Biol. Cell. 95, 425-436. doi: 10.1016/s0248-4900(03)00072-8

Mehlen, P., and Tauszig-Delamasure, S. (2014). Dependence receptors and colorectal cancer. Gut 63, 1821-1829. doi: 10.1136/gutjnl-2013-306704

Miki, Y., Swensen, J., Shattuck-Eidens, D., Futreal, P. A., Harshman, K., Tavtigian, S., et al. (1994). A strong candidate for the breast and ovarian cancer susceptibility gene BRCA1. Science 266, 66-71. doi: 10.1126/science.7545954

Milbrandt, J., de Sauvage, F. J., Fahrner, T. J., Baloh, R. H., Leitner, M. L., Tansey, M. G., et al. (1998). Persephin, a novel neurotrophic factor related to GDNF and neurturin. Neuron 20, 245-253. doi: 10.1016/s0896-6273(00) 80453-5

Miletic, G., and Miletic, V. (2002). Increases in the concentration of brain derived neurotrophic factor in the lumbar spinal dorsal horn are associated with pain behavior following chronic constriction injury in rats. Neurosci. Lett. 319, 137-140. doi: 10.1016/s0304-3940(01)02576-9

Millaruelo, A. I., Nieto-Sampedro, M., Yu, J., and Cotman, C. W. (1986). Neurotrophic activity in the central and peripheral nervous systems of the cat. Effects of injury. Brain Res. 374, 12-20. doi: 10.1016/0006-8993(86) 90389-6

Mills, C. D., Allchorne, A. J., Griffin, R. S., Woolf, C. J., and Costigan, M. (2007). GDNF selectively promotes regeneration of injury-primed sensory neurons in the lesioned spinal cord. Mol. Cell. Neurosci. 36, 185-194. doi: 10.1016/j.mcn. 2007.06.011

Mitsumoto, H., Klinkosz, B., Pioro, E. P., Tsuzaka, K., Ishiyama, T., O’Leary, R. M., et al. (2001). Effects of cardiotrophin-1 (CT-1) in a mouse motor neuron disease. Muscle Nerve 24, 769-777. doi: 10.1002/mus.1068

Mizisin, A. P., Vu, Y., Shuff, M., and Calcutt, N. A. (2004). Ciliary neurotrophic factor improves nerve conduction and ameliorates regeneration deficits in diabetic rats. Diabetes 53, 1807-1812. doi: 10.2337/diabetes.53. 7.1807

Moore, S. W., Tessier-Lavigne, M., and Kennedy, T. E. (2007). Netrins and their receptors. Adv. Exp. Med. Biol. 621, 17-31. doi: 10.1007/978-0-387-76715-4_2

Morikawa, Y. (2005). Oncostatin M in the development of the nervous system. Anat. Sci. Int. 80, 53-59. doi: 10.1111/j.1447-073x.2005.00100.x

Morikawa, Y., Tamura, S., Minehata, K., Donovan, P. J., Miyajima, A., and Senba, E. (2004). Essential function of oncostatin $\mathrm{m}$ in nociceptive neurons of dorsal root ganglia. J. Neurosci. 24, 1941-1947. doi: 10.1523/JNEUROSCI. 4975-03.2004

Morrison, E. E., Askham, J., Clissold, P., Markham, A. F., and Meredith, D. M. (1997a). Expression of $\beta$-catenin and the adenomatous polyposis coli tumour suppressor protein in mouse neocortical cells in vitro. Neurosci. Lett. 235, 129-132. doi: 10.1016/s0304-3940(97)00739-8

Morrison, E. E., Askham, J., Clissold, P., Markham, A. F., and Meredith, D. M. (1997b). The cellular distribution of the adenomatous polyposis coli tumour suppressor protein in neuroblastoma cells is regulated by microtubule dynamics. Neuroscience 81, 553-563. doi: 10.1016/s0306-4522(97) 00099-7

Morrison, R. S., Sharma, A., de Vellis, J., and Bradshaw, R. A. (1986). Basic fibroblast growth factor supports the survival of cerebral cortical neurons in primary culture. Proc. Natl. Acad. Sci. U S A 83, 7537-7541. doi: 10.1073/pnas. 83.19.7537

Mosley, B., De Imus, C., Friend, D., Boiani, N., Thoma, B., Park, L. S., et al. (1996). Dual oncostatin M (OSM) receptors. Cloning and characterization of an alternative signaling subunit conferring OSM-specific receptor activation. J. Biol. Chem. 271, 32635-32643. doi: 10.1074/jbc.271.51.32635

Mueller, B. K., Mack, H., and Teusch, N. (2005). Rho kinase, a promising drug target for neurological disorders. Nat. Rev. Drug Discov. 4, 387-398. doi: $10.1038 / \mathrm{nrd} 1719$

Müller, A., Hauk, T. G., Leibinger, M., Marienfeld, R., and Fischer, D. (2009). Exogenous CNTF stimulates axon regeneration of retinal ganglion cells partially via endogenous CNTF. Mol. Cell. Neurosci. 41, 233-246. doi: 10.1016/j. mcn.2009.03.002 
Murphy, M., Reid, K., Brown, M. A., and Bartlett, P. F. (1993). Involvement of leukemia inhibitory factor and nerve growth factor in the development of dorsal root ganglion neurons. Development 117, 1173-1182.

Murphy, M., Reid, K., Hilton, D. J., and Bartlett, P. F. (1991). Generation of sensory neurons is stimulated by leukemia inhibitory factor. Proc. Natl. Acad. Sci. U S A 88, 3498-3501. doi: 10.1073/pnas.88.8.3498

Musatov, S., Roberts, J., Brooks, A. I., Pena, J., Betchen, S., Pfaff, D. W., et al. (2004). Inhibition of neuronal phenotype by PTEN in PC12 cells. Proc. Natl. Acad. Sci. U S A 101, 3627-3631. doi: 10.1073/pnas.0308289101

Nakamura, T., Nishizawa, T., Hagiya, M., Seki, T., Shimonishi, M., Sugimura, A., et al. (1989). Molecular cloning and expression of human hepatocyte growth factor. Nature 342, 440-443. doi: 10.1038/342440a0

Nakamura, T., Teramoto, H., Tomita, Y., and Ichihara, A. (1984). L-proline is an essential amino acid for hepatocyte growth in culture. Biochem. Biophys. Res. Commun. 122, 884-891. doi: 10.1016/0006-291x(84)91173-2

Namaka, M. P., Sawchuk, M., MacDonald, S. C., Jordan, L. M., and Hochman, S. (2001). Neurogenesis in postnatal mouse dorsal root ganglia. Exp. Neurol. 172, 60-69. doi: 10.1006/exnr.2001.7761

Narciso, M. S., Mietto Bde, S., Marques, S. A., Soares, C. P., Mermelstein Cdos, S., El-Cheikh, M. C., et al. (2009). Sciatic nerve regeneration is accelerated in galectin-3 knockout mice. Exp. Neurol. 217, 7-15. doi: 10.1016/j.expneurol. 2009.01.008

Nijs, J., Meeus, M., Versijpt, J., Moens, M., Bos, I., Knaepen, K., et al. (2015). Brain-derived neurotrophic factor as a driving force behind neuroplasticity in neuropathic and central sensitization pain: a new therapeutic target? Expert Opin. Ther. Targets 19, 565-576. doi: 10.1517/14728222.2014.994506

Ning, K., Drepper, C., Valori, C. F., Ahsan, M., Wyles, M., Higginbottom, A., et al. (2010). PTEN depletion rescues axonal growth defect and improves survival in SMN-deficient motor neurons. Hum. Mol. Genet. 19, 3159-3168. doi: $10.1093 / \mathrm{hmg} / \mathrm{ddq} 226$

Nix, W. A., and Hopf, H. C. (1983). Electrical stimulation of regenerating nerve and its effect on motor recovery. Brain Res. 272, 21-25. doi: 10.1016/00068993(83)90360-8

Noristani, H. N., Gerber, Y. N., Sabourin, J. C., Le Corre, M., Lonjon, N., MestreFrances, N., et al. (2017). RNA-seq analysis of microglia reveals time-dependent activation of specific genetic programs following spinal cord injury. Front. Mol. Neurosci. 10:90. doi: 10.3389/fnmol.2017.00090

Ogai, K., Kuwana, A., Hisano, S., Nagashima, M., Koriyama, Y., Sugitani, K., et al. (2014). Upregulation of leukemia inhibitory factor (LIF) during the early stage of optic nerve regeneration in zebrafish. PLoS One 9:e106010. doi: 10.1371/journal.pone.0106010

Omodaka, K., Kurimoto, T., Nakamura, O., Sato, K., Yasuda, M., Tanaka, Y., et al. (2014). Artemin augments survival and axon regeneration in axotomized retinal ganglion cells. J. Neurosci. Res. 92, 1637-1646. doi: 10.1002/jnr.23449

Oppenheim, R. W., Wiese, S., Prevette, D., Armanini, M., Wang, S., Houenou, L. J., et al. (2001). Cardiotrophin-1, a muscle-derived cytokine, is required for the survival of subpopulations of developing motoneurons. J. Neurosci. 21, 1283-1291. doi: 10.1523/JNEUROSCI.21-04-01283.2001

Ornitz, D. M., and Itoh, N. (2015). The fibroblast growth factor signaling pathway. Wiley Interdiscip. Rev. Dev. Biol. 4, 215-266. doi: 10.1002/wdev.176

Ortmann, S. D., and Hellenbrand, D. J. (2018). Glial cell line-derived neurotrophic factor as a treatment after spinal cord injury. Neural Regen. Res. 13, 1733-1734. doi: 10.4103/1673-5374.238610

Pajcini, K. V., Corbel, S. Y., Sage, J., Pomerantz, J. H., and Blau, H. M. (2010). Transient inactivation of $\mathrm{Rb}$ and ARF yields regenerative cells from postmitotic mammalian muscle. Cell Stem Cell 7, 198-213. doi: 10.1016/j.stem.2010.05.022

Pao, G. M., Zhu, Q., Perez-Garcia, C. G., Chou, S. J., Suh, H., Gage, F. H., et al. (2014). Role of BRCA1 in brain development. Proc. Natl. Acad. Sci. U S A 111, E1240-E1248. doi: 10.1073/pnas.1400783111

Park, J. I., Seo, I. A., Lee, H. K., Park, H. T., Shin, S. W., Park, Y. M., et al. (2007). Netrin inhibits regenerative axon growth of adult dorsal root ganglion neurons in vitro. J. Korean Med. Sci. 22, 641-645. doi: 10.3346/jkms.2007.22.4.641

Park, K. K., Liu, K., Hu, Y., Smith, P. D., Wang, C., Cai, B., et al. (2008). Promoting axon regeneration in the adult CNS by modulation of the PTEN/mTOR pathway. Science 322, 963-966. doi: 10.1126/science.1161566

Patapoutian, A., and Reichardt, L. F. (2000). Roles of Wnt proteins in neural development and maintenance. Curr. Opin. Neurobiol. 10, 392-399. doi: 10.1016/s0959-4388(00)00100-8
Peng, Y. R., He, S., Marie, H., Zeng, S. Y., Ma, J., Tan, Z. J., et al. (2009). Coordinated changes in dendritic arborization and synaptic strength during neural circuit development. Neuron 61, 71-84. doi: 10.1016/j.neuron.2008. 11.015

Pennica, D., Arce, V., Swanson, T. A., Vejsada, R., Pollock, R. A., Armanini, M., et al. (1996). Cardiotrophin-1, a cytokine present in embryonic muscle, supports long-term survival of spinal motoneurons. Neuron 17, 63-74. doi: 10.1016/s0896-6273(00)80281-0

Pennica, D., Shaw, K. J., Swanson, T. A., Moore, M. W., Shelton, D. L. Zioncheck, K. A., et al. (1995). Cardiotrophin-1. Biological activities and binding to the leukemia inhibitory factor receptor/gp130 signaling complex. J. Biol. Chem. 270, 10915-10922. doi: 10.1074/jbc.270.18.10915

Plata-Salamán, C. R. (1991). Epidermal growth factor and the nervous system. Peptides 12, 653-663. doi: 10.1016/0196-9781(91)90115-6

Pockett, S., and Gavin, R. M. (1985). Acceleration of peripheral nerve regeneration after crush injury in rat. Neurosci. Lett. 59, 221-224. doi: 10.1016/03043940(85)90203-4

Podsypanina, K., Ellenson, L. H., Nemes, A., Gu, J., Tamura, M., Yamada, K. M., et al. (1999). Mutation of Pten/Mmacl in mice causes neoplasia in multiple organ systems. Proc. Natl. Acad. Sci. U S A 96, 1563-1568. doi: 10.1073/pnas. 96.4.1563

Pulvers, J. N., and Huttner, W. B. (2009). Brcal is required for embryonic development of the mouse cerebral cortex to normal size by preventing apoptosis of early neural progenitors. Development 136, 1859-1868. doi: 10.1242/dev.033498

Ramer, M. S., Duraisingam, I., Priestley, J. V., and McMahon, S. B. (2001). Twotiered inhibition of axon regeneration at the dorsal root entry zone. J. Neurosci. 21, 2651-2660. doi: 10.1523/JNEUROSCI.21-08-02651.2001

Rende, M., Hagg, T., Manthorpe, M., and Varon, S. (1992a). Nerve growth factor receptor immunoreactivity in neurons of the normal adult rat spinal cord and its modulation after peripheral nerve lesions. J. Comp. Neurol. 319, 285-298. doi: 10.1002/cne.903190208

Rende, M., Muir, D., Ruoslahti, E., Hagg, T., Varon, S., and Manthorpe, M. (1992b). Immunolocalization of ciliary neuronotrophic factor in adult rat sciatic nerve. Glia 5, 25-32. doi: 10.1002/glia.440050105

Reyes-Corona, D., Vázquez-Hernández, N., Escobedo, L., Orozco-Barrios, C. E., Ayala-Davila, J., Moreno, M. G., et al. (2017). Neurturin overexpression in dopaminergic neurons induces presynaptic and postsynaptic structural changes in rats with chronic 6-hydroxydopamine lesion. PLoS One 12:e0188239. doi: 10.1371/journal.pone.0188239

Rich, K. M., Luszczynski, J. R., Osborne, P. A., and Johnson, E. M. Jr. (1987). Nerve growth factor protects adult sensory neurons from cell death and atrophy caused by nerve injury. J. Neurocytol. 16, 261-268. doi: 10.1007/bf01795309

Richardson, P. M., and Ebendal, T. (1982). Nerve growth activities in rat peripheral nerve. Brain Res. 246, 57-64. doi: 10.1016/0006-8993(82)90141-x

Robledo, O., Fourcin, M., Chevalier, S., Guillet, C., Auguste, P., PouplardBarthelaix, A., et al. (1997). Signaling of the cardiotrophin-1 receptor. Evidence for a third receptor component. J. Biol. Chem. 272, 4855-4863. doi: 10.1074/jbc. 272.8.4855

Rodgers, E. E., and Theibert, A. B. (2002). Functions of PI 3-kinase in development of the nervous system. Int. J. Dev. Neurosci. 20, 187-197. doi: 10.1016/s07365748(02)00047-3

Rosenthal, A., Goeddel, D. V., Nguyen, T., Lewis, M., Shih, A., Laramee, G. R., et al. (1990). Primary structure and biological activity of a novel human neurotrophic factor. Neuron 4, 767-773. doi: 10.1016/0896-6273(90)90203-r

Rulifson, E. J., Kim, S. K., and Nusse, R. (2002). Ablation of insulin-producing neurons in flies: growth and diabetic phenotypes. Science 296, 1118-1120. doi: $10.1126 /$ science. 1070058

Sage, J. (2012). The retinoblastoma tumor suppressor and stem cell biology. Genes Dev. 26, 1409-1420. doi: 10.1101/gad.193730.112

Sage, J., Miller, A. L., Pérez-Mancera, P. A., Wysocki, J. M., and Jacks, T. (2003). Acute mutation of retinoblastoma gene function is sufficient for cell cycle reentry. Nature 424, 223-228. doi: 10.1038/nature01764

Sahenk, Z., Seharaseyon, J., and Mendell, J. R. (1994). CNTF potentiates peripheral nerve regeneration. Brain Res. 655, 246-250. doi: 10.1016/0006-8993(94) 91621-7

Saleh, A., Roy Chowdhury, S. K., Smith, D. R., Balakrishnan, S., Tessler, L., Martens, C., et al. (2013). Ciliary neurotrophic factor activates NF- $\kappa$ B to 
enhance mitochondrial bioenergetics and prevent neuropathy in sensory neurons of streptozotocin-induced diabetic rodents. Neuropharmacology 65, 65-73. doi: 10.1016/j.neuropharm.2012.09.015

Sango, K., Yanagisawa, H., and Takaku, S. (2007). Expression and histochemical localization of ciliary neurotrophic factor in cultured adult rat dorsal root ganglion neurons. Histochem. Cell Biol. 128, 35-43. doi: 10.1007/s00418-0070290-X

Santos, D., González-Pérez, F., Giudetti, G., Micera, S., Udina, E., Del Valle, J., et al. (2017). Preferential enhancement of sensory and motor axon regeneration by combining extracellular matrix components with neurotrophic factors. Int. J. Mol. Sci. 18:E65. doi: 10.3390/ijms18010065

Sawai, H., Clarke, D. B., Kittlerova, P., Bray, G. M., and Aguayo, A. J. (1996). Brainderived neurotrophic factor and neurotrophin $-4 / 5$ stimulate growth of axonal branches from regenerating retinal ganglion cells. J. Neurosci. 16, 3887-3894. doi: 10.1523/JNEUROSCI.16-12-03887.1996

Schnell, L., Schneider, R., Kolbeck, R., Barde, Y. A., and Schwab, M. E. (1994). Neurotrophin-3 enhances sprouting of corticospinal tract during development and after adult spinal cord lesion. Nature 367, 170-173. doi: 10.1038/367 $170 \mathrm{a} 0$

Senaldi, G., Varnum, B. C., Sarmiento, U., Starnes, C., Lile, J., Scully, S., et al. (1999). Novel neurotrophin-1/B cell-stimulating factor-3: a cytokine of the IL-6 family. Proc. Natl. Acad. Sci. U S A 96, 11458-11463. doi: 10.1073/pnas.96.20. 11458

Sendtner, M., Kreutzberg, G. W., and Thoenen, H. (1990). Ciliary neurotrophic factor prevents the degeneration of motor neurons after axotomy. Nature 345, 440-441. doi: 10.1038/345440a0

Sendtner, M., Stöckli, K. A., and Thoenen, H. (1992). Synthesis and localization of ciliary neurotrophic factor in the sciatic nerve of the adult rat after lesion and during regeneration. J. Cell Biol. 118, 139-148. doi: 10.1083/jcb.118.1.139

Serafini, T., Kennedy, T. E., Galko, M. J., Mirzayan, C., Jessell, T. M., and TessierLavigne, M. (1994). The netrins define a family of axon outgrowth-promoting proteins homologous to C. elegans UNC-6. Cell 78, 409-424. doi: 10.1016/00928674(94)90420-0

Shelton, D. N., Sandoval, I. T., Eisinger, A., Chidester, S., Ratnayake, A., Ireland, C. M., et al. (2006). Up-regulation of CYP26A1 in adenomatous polyposis coli-deficient vertebrates via a WNT-dependent mechanism: implications for intestinal cell differentiation and colon tumor development. Cancer Res. 66, 7571-7577. doi: 10.1158/0008-5472.can-06-1067

Shettar, A., and Muttagi, G. (2012). Developmental regulation of insulin receptor gene in sciatic nerves and role of insulin on glycoprotein P0 in the Schwann cells. Peptides 36, 46-53. doi: 10.1016/j.peptides.2012.04.012

Shin, S. L., Cha, J. H., Chun, M. H., Chung, J. W., and Lee, M. Y. (1999). Expression of osteopontin mRNA in the adult rat brain. Neurosci. Lett. 273, 73-76. doi: 10.1016/s0304-3940(99)00516-9

Sikandar, S., Minett, M. S., Millet, Q., Santana-Varela, S., Lau, J., Wood, J. N., et al. (2018). Brain-derived neurotrophic factor derived from sensory neurons plays a critical role in chronic pain. Brain 141, 1028-1039. doi: 10.1093/brain/awy009

Singh, B., Krishnan, A., Micu, I., Koshy, K., Singh, V., Martinez, J. A., et al. (2015). Peripheral neuron plasticity is enhanced by brief electrical stimulation and overrides attenuated regrowth in experimental diabetes. Neurobiol. Dis. 83, 134-151. doi: 10.1016/j.nbd.2015.08.009

Singh, B., Singh, V., Krishnan, A., Koshy, K., Martinez, J. A., Cheng, C., et al. (2014). Regeneration of diabetic axons is enhanced by selective knockdown of the PTEN gene. Brain 137, 1051-1067. doi: 10.1093/brain/awu031

Singh, B., Xu, Q. G., Franz, C. K., Zhang, R., Dalton, C., Gordon, T., et al. (2012a). Accelerated axon outgrowth, guidance, and target reinnervation across nerve transection gaps following a brief electrical stimulation paradigm. J. Neurosurg. 116, 498-512. doi: 10.3171/2011.10.jns11612

Singh, B., Xu, Y., McLaughlin, T., Singh, V., Martinez, J. A., Krishnan, A., et al. (2012b). Resistance to trophic neurite outgrowth of sensory neurons exposed to insulin. J. Neurochem. 121, 263-276. doi: 10.1111/j.1471-4159.2012.07681.x

Singhal, A., Cheng, C., Sun, H., and Zochodne, D. W. (1997). Near nerve local insulin prevents conduction slowing in experimental diabetes. Brain Res. 763, 209-214. doi: 10.1016/s0006-8993(97)00412-5

Slack, R. S., El-Bizri, H., Wong, J., Belliveau, D. J., and Miller, F. D. (1998). A critical temporal requirement for the retinoblastoma protein family during neuronal determination. J. Cell Biol. 140, 1497-1509. doi: 10.1083/jcb.140. 6.1497
Song, X. Y., Li, F., Zhang, F. H., Zhong, J. H., and Zhou, X. F. (2008). Peripherallyderived bdnf promotes regeneration of ascending sensory neurons after spinal cord injury. PLoS One 3:e1707. doi: 10.1371/journal.pone.0001707

Stöckli, K. A., Lillien, L. E., Näher-Noé, M., Breitfeld, G., Hughes, R. A., Raff, M. C., et al. (1991). Regional distribution, developmental changes, and cellular localization of CNTF-mRNA and protein in the rat brain. J. Cell Biol. 115, 447-459. doi: 10.1083/jcb.115.2.447

Strand, N. S., Hoi, K. K., Phan, T. M. T., Ray, C. A., Berndt, J. D., and Moon, R. T. (2016). Wnt/ $\beta$-catenin signaling promotes regeneration after adult zebrafish spinal cord injury. Biochem. Biophys. Res. Commun. 477, 952-956. doi: 10.1016/j.bbrc.2016.07.006

Sugimoto, K., Murakawa, Y., and Sima, A. A. (2002). Expression and localization of insulin receptor in rat dorsal root ganglion and spinal cord. J. Peripher. Nerv. Syst. 7, 44-53. doi: 10.1046/j.1529-8027.2002.02005.x

Sugimoto, K., Murakawa, Y., Zhang, W., Xu, G., and Sima, A. A. (2000). Insulin receptor in rat peripheral nerve: its localization and alternatively spliced isoforms. Diabetes Metab. Res. Rev. 16, 354-363. doi: 10.1002/15207560(200009/10)16:5<354::aid-dmrr149>3.0.co;2-h

Sulaiman, O. A., and Gordon, T. (2000). Effects of short- and long-term schwann cell denervation on peripheral nerve regeneration, myelination, and size. Glia 32, 234-246. doi: 10.1002/1098-1136(200012)32:3<234::aid-glia40>3.0.co;2-3

Sun, K. L. W., Correia, J. P., and Kennedy, T. E. (2011). Netrins: versatile extracellular cues with diverse functions. Development 138, 2153-2169. doi: 10.1242/dev.044529

Taga, T., and Kishimoto, T. (1997). Gp130 and the interleukin-6 family of cytokines. Annu. Rev. Immunol. 15, 797-819. doi: 10.1146/annurev.immunol. 15.1.797

Takaku, S., Yanagisawa, H., Watabe, K., Horie, H., Kadoya, T., Sakumi, K., et al. (2013). GDNF promotes neurite outgrowth and upregulates galectin-1 through the RET/PI3K signaling in cultured adult rat dorsal root ganglion neurons. Neurochem. Int. 62, 330-339. doi: 10.1016/j.neuint.2013.01.008

Tamura, S., Morikawa, Y., Miyajima, A., and Senba, E. (2003). Expression of oncostatin $M$ receptor $\beta$ in a specific subset of nociceptive sensory neurons. Eur. J. Neurosci. 17, 2287-2298. doi: 10.1046/j.1460-9568.2003.02681.x

Tannemaat, M. R., Eggers, R., Hendriks, W. T., de Ruiter, G. C., van Heerikhuize, J. J., Pool, C. W., et al. (2008). Differential effects of lentiviral vector-mediated overexpression of nerve growth factor and glial cell line-derived neurotrophic factor on regenerating sensory and motor axons in the transected peripheral nerve. Eur. J. Neurosci. 28, 1467-1479. doi: 10.1111/j. 1460-9568.2008.06452.x

Tawk, M., Makoukji, J., Belle, M., Fonte, C., Trousson, A., Hawkins, T., et al. (2011). Wnt/ $\beta$-catenin signaling is an essential and direct driver of myelin gene expression and myelinogenesis. J. Neurosci. 31, 3729-3742. doi: 10.1523/JNEUROSCI.4270-10.2011

Terashima, T., Yasuda, H., Terada, M., Kogawa, S., Maeda, K., Haneda, M., et al. (2001). Expression of Rho-family GTPases (Rac, cdc42, RhoA) and their association with p-21 activated kinase in adult rat peripheral nerve. J. Neurochem. 77, 986-993. doi: 10.1046/j.1471-4159.2001.00336.x

Tham, S., Dowsing, B., Finkelstein, D., Donato, R., Cheema, S. S., Bartlett, P. F., et al. (1997). Leukemia inhibitory factor enhances the regeneration of transected rat sciatic nerve and the function of reinnervated muscle. J. Neurosci. Res. 47, 208-215. doi: 10.1002/(sici)1097-4547(19970115)47:2<208::aidjnr9>3.0.co; $2-\mathrm{j}$

Thoenen, H. (1995). Neurotrophins and neuronal plasticity. Science 270, 593-598. doi: $10.1126 /$ science.270.5236.593

Toma, J. G., Pareek, S., Barker, P., Mathew, T. C., Murphy, R. A., Acheson, A., et al. (1992). Spatiotemporal increases in epidermal growth factor receptors following peripheral nerve injury. J. Neurosci. 12, 2504-2515. doi: 10.1523/JNEUROSCI.12-07-02504.1992

Tomac, A., Lindqvist, E., Lin, L. F., Ogren, S. O., Young, D., Hoffer, B. J., et al. (1995). Protection and repair of the nigrostriatal dopaminergic system by GDNF in vivo. Nature 373, 335-339. doi: 10.1038/373335a0

Tonra, J. R., Curtis, R., Wong, V., Cliffer, K. D., Park, J. S., Timmes, A., et al. (1998). Axotomy upregulates the anterograde transport and expression of brainderived neurotrophic factor by sensory neurons. J. Neurosci. 18, 4374-4383. doi: 10.1523/JNEUROSCI.18-11-04374.1998

Toth, C., Brussee, V., Martinez, J. A., McDonald, D., Cunningham, F. A., and Zochodne, D. W. (2006). Rescue and regeneration of injured peripheral 
nerve axons by intrathecal insulin. Neuroscience 139, 429-449. doi: 10.1016/j. neuroscience.2005.11.065

Trupp, M., Rydén, M., Jörnvall, H., Funakoshi, H., Timmusk, T., Arenas, E., et al. (1995). Peripheral expression and biological activities of GDNF, a new neurotrophic factor for avian and mammalian peripheral neurons. J. Cell Biol. 130, 137-148. doi: 10.1083/jcb.130.1.137

Tsujii, M., Akeda, K., Iino, T., and Uchida, A. (2009). Are BMPs involved in normal nerve and following transection?: a pilot study. Clin. Orthop. Relat. Res. 467, 3183-3189. doi: 10.1007/s11999-009-1009-1

Unsicker, K., Reichert-Preibsch, H., Schmidt, R., Pettmann, B., Labourdette, G., and Sensenbrenner, M. (1987). Astroglial and fibroblast growth factors have neurotrophic functions for cultured peripheral and central nervous system neurons. Proc. Natl. Acad. Sci. U S A 84, 5459-5463. doi: 10.1073/pnas. 84.15.5459

Vellani, V., Zachrisson, O., and McNaughton, P. A. (2004). Functional bradykinin B1 receptors are expressed in nociceptive neurones and are upregulated by the neurotrophin GDNF. J. Physiol. 560, 391-401. doi: 10.1113/jphysiol.2004. 067462

Verge, V. M., Riopelle, R. J., and Richardson, P. M. (1989). Nerve growth factor receptors on normal and injured sensory neurons. J. Neurosci. 9, 914-922. doi: 10.1523/JNEUROSCI.09-03-00914.1989

Walicke, P., Cowan, W. M., Ueno, N., Baird, A., and Guillemin, R. (1986). Fibroblast growth factor promotes survival of dissociated hippocampal neurons and enhances neurite extension. Proc. Natl. Acad. Sci. U S A 83, 3012-3016. doi: 10.1073/pnas.83.9.3012

Walicke, P. A., Feige, J. J., and Baird, A. (1989). Characterization of the neuronal receptor for basic fibroblast growth factor and comparison to receptors on mesenchymal cells. J. Biol. Chem. 264, 4120-4126.

Walker, C. L., Walker, M. J., Liu, N. K., Risberg, E. C., Gao, X., Chen, J., et al. (2012). Systemic bisperoxovanadium activates Akt/mTOR, reduces autophagy and enhances recovery following cervical spinal cord injury. PLoS One 7:e30012. doi: 10.1371/journal.pone.0030012

Waller, A. (1850). Experiments on the section of the glossopharyngeal and hypoglossal nerves of the frog and observations of the alterations produced thereby in the structure of their primitive fibres. Philos. Trans. R. Soc. Lond. 140, 423-429. doi: 10.1098/rstl.1850.0021

Wan, L., Xia, R., and Ding, W. (2010). Short-term low-frequency electrical stimulation enhanced remyelination of injured peripheral nerves by inducing the promyelination effect of brain-derived neurotrophic factor on Schwann cell polarization. J. Neurosci. Res. 88, 2578-2587. doi: 10.1002/jnr.22426

Wang, R., King, T., Ossipov, M. H., Rossomando, A. J., Vanderah, T. W., Harvey, P., et al. (2008). Persistent restoration of sensory function by immediate or delayed systemic artemin after dorsal root injury. Nat. Neurosci. 11, 488-496. doi: 10.1038/nn2069

Wang, R., Rossomando, A., Sah, D. W., Ossipov, M. H., King, T., and Porreca, F. (2014). Artemin induced functional recovery and reinnervation after partial nerve injury. Pain 155, 476-484. doi: 10.1016/j.pain.2013.11.007

Wang, Y. L., Wang, D. Z., Nie, X., Lei, D. L., Liu, Y. P., Zhang, Y. J., et al. (2007). The role of bone morphogenetic protein-2 in vivo in regeneration of peripheral nerves. Br. J. Oral Maxillofac. Surg. 45, 197-202. doi: 10.1016/j.bjoms.2006. 06.003

Wang, Q., Xu, L., Chen, P., Xu, Z., Qiu, J., Ge, J., et al. (2018). Brcal is upregulated by 5 -Aza-CdR and promotes DNA repair and cell survival and inhibits neurite outgrowth in rat retinal neurons. Int. J. Mol. Sci. 19:E1214. doi: 10.3390/ijms 19041214

Wanigasekara, Y., Airaksinen, M. S., Heuckeroth, R. O., Milbrandt, J., and Keast, J. R. (2004). Neurturin signalling via GFR $\alpha 2$ is essential for innervation of glandular but not muscle targets of sacral parasympathetic ganglion neurons. Mol. Cell Neurosci. 25, 288-300. doi: 10.1016/j.mcn.2003. 10.019

Watanabe, K., Tamamaki, N., Furuta, T., Ackerman, S. L., Ikenaka, K., and Ono, K. (2006). Dorsally derived netrin 1 provides an inhibitory cue and elaborates the 'waiting period' for primary sensory axons in the developing spinal cord. Development 133, 1379-1387. doi: 10.1242/dev.02312

Webber, C. A., Christie, K. J., Cheng, C., Martinez, J. A., Singh, B., Singh, V., et al. (2011). Schwann cells direct peripheral nerve regeneration through the Netrin-1 receptors, DCC and Unc5H2. Glia 59, 1503-1517. doi: 10.1002/glia. 21194
Wehner, D., Tsarouchas, T. M., Michael, A., Haase, C., Weidinger, G., Reimer, M. M., et al. (2017). Wnt signaling controls pro-regenerative Collagen $\mathrm{XII}$ in functional spinal cord regeneration in zebrafish. Nat. Commun. 8:126. doi: 10.1038/s41467-017-00143-0

Weiss, T. W., Samson, A. L., Niego, B., Daniel, P. B., and Medcalf, R. L. (2006). Oncostatin $M$ is a neuroprotective cytokine that inhibits excitotoxic injury in vitro and in vivo. FASEB J. 20, 2369-2371. doi: 10.1096/fj.065850fje

Widenfalk, J., Wu, W., Hao, J., Person, J. K., Wiesenfeldt-Hallin, Z., and Risling, M. (2009). Treatment of transected peripheral nerves with artemin improved motor neuron regeneration, but did not reduce nerve injury-induced pain behaviour. Scand. J. Plast. Reconstr. Surg. Hand. Surg. 43, 245-250. doi: 10.3109/02844310903259082

Williams, L. R., Manthorpe, M., Barbin, G., Nieto-Sampedro, M., Cotman, C. W., and Varon, S. (1984). High ciliary neuronotrophic specific activity in rat peripheral nerve. Int. J. Dev. Neurosci. 2, 177-180. doi: 10.1016/07365748(84)90009-1

Witzel, C., Rohde, C., and Brushart, T. M. (2005). Pathway sampling by regenerating peripheral axons. J. Comp. Neurol. 485, 183-190. doi: 10.1002/cne. 20436

Wong, L. E., Gibson, M. E., Arnold, H. M., Pepinsky, B., and Frank, E. (2015). Artemin promotes functional long-distance axonal regeneration to the brainstem after dorsal root crush. Proc. Natl. Acad. Sci. U S A 112, 6170-6175. doi: 10.1073/pnas.1502057112

Wong, R. W., and Guillaud, L. (2004). The role of epidermal growth factor and its receptors in mammalian CNS. Cytokine Growth Factor Rev. 15, 147-156. doi: 10.1016/j.cytogfr.2004.01.004

Wong, B. J., and Mattox, D. E. (1991). Experimental nerve regeneration: a review. Otolaryngol. Clin. North Am. 24, 739-752.

Wong, J. N., Olson, J. L., Morhart, M. J., and Chan, K. M. (2015). Electrical stimulation enhances sensory recovery: a randomized controlled trial. Ann. Neurol. 77, 996-1006. doi: 10.1002/ana.24397

Wright, M. C., Mi, R., Connor, E., Reed, N., Vyas, A., Alspalter, M., et al. (2014). Novel roles for osteopontin and clusterin in peripheral motor and sensory axon regeneration. J. Neurosci. 34, 1689-1700. doi: 10.1523/JNEUROSCI.382213.2014

Wung, J. K., Perry, G., Kowalski, A., Harris, P. L., Bishop, G. M., Trivedi, M. A., et al. (2007). Increased expression of the remodeling- and tumorigenicassociated factor osteopontin in pyramidal neurons of the Alzheimer's disease brain. Curr. Alzheimer Res. 4, 67-72. doi: 10.2174/1567205077799 39869

Xu, X. M., Guénard, V., Kleitman, N., Aebischer, P., and Bunge, M. B. (1995). A combination of BDNF and NT-3 promotes supraspinal axonal regeneration into Schwann cell grafts in adult rat thoracic spinal cord. Exp. Neurol. 134, 261-272. doi: 10.1006/exnr.1995.1056

Xu, Q. G., Li, X. Q., Kotecha, S. A., Cheng, C., Sun, H. S., and Zochodne, D. W. (2004). Insulin as an in vivo growth factor. Exp. Neurol. 188, 43-51. doi: 10.1016/j.expneurol.2004.03.008

Yajima, Y., Narita, M., Narita, M., Matsumoto, N., and Suzuki, T. (2002). Involvement of a spinal brain-derived neurotrophic factor/full-length TrkB pathway in the development of nerve injury-induced thermal hyperalgesia in mice. Brain Res. 958, 338-346. doi: 10.1016/s0006-8993(02) 03666-1

Yamada, M., Ikeuchi, T., and Hatanaka, H. (1997). The neurotrophic action and signalling of epidermal growth factor. Prog. Neurobiol. 51, 19-37. doi: 10.1016/s0301-0082(96)00046-9

Yamamoto, M., Sobue, G., Yamamoto, K., Terao, S., and Mitsuma, T. (1996). Expression of mRNAs for neurotrophic factors (NGF, BDNF, NT-3 and GDNF) and their receptors (p75NGFR, trkA, trkB, and trkC) in the adult human peripheral nervous system and nonneural tissues. Neurochem. Res. 21, 929-938. doi: 10.1007/bf02532343

Yan, Q., Matheson, C., and Lopez, O. T. (1995). In vivo neurotrophic effects of GDNF on neonatal and adult facial motor neurons. Nature 373, 341-344. doi: 10.1038/373341a0

Yang, Q., Peng, L., Wu, Y., Li, Y., Wang, L., Luo, J. H., et al. (2018). Endocytic adaptor protein HIP1R controls intracellular trafficking of epidermal growth factor receptor in neuronal dendritic development. Front. Mol. Neurosci. 11:447. doi: 10.3389/fnmol.2018.00447 
Yin, Q., Kemp, G. J., Yu, L. G., Wagstaff, S. C., and Frostick, S. P. (2001). Neurotrophin-4 delivered by fibrin glue promotes peripheral nerve regeneration. Muscle Nerve 24, 345-351. doi: 10.1002/10974598(200103)24:3<345::aid-mus1004>3.0.co;2-p

Yin, X. F., Xu, H. M., Jiang, Y. X., Zhi, Y. L., Liu, Y. X., Xiang, H. W., et al. (2015). Lentivirus-mediated Persephin over-expression in Parkinson's disease rats. Neural Regen Res. 10, 1814-1818. doi: 10.4103/1673-5374.170309

Yoshimura, T., Kawano, Y., Arimura, N., Kawabata, S., Kikuchi, A., and Kaibuchi, K. (2005). GSK-3 $\beta$ regulates phosphorylation of CRMP-2 and neuronal polarity. Cell 120, 137-149. doi: 10.1016/j.cell.2004.11.012

Zacksenhaus, E., Jiang, Z., Chung, D., Marth, J. D., Phillips, R. A., and Gallie, B. L. (1996). pRb controls proliferation, differentiation, and death of skeletal muscle cells and other lineages during embryogenesis. Genes Dev. 10, 3051-3064. doi: 10.1101/gad.10.23.3051

Zhang, J., Gray, J., Wu, L., Leone, G., Rowan, S., Cepko, C. L., et al. (2004a). Rb regulates proliferation and rod photoreceptor development in the mouse retina. Nat. Genet. 36, 351-360. doi: 10.1038/ng1318

Zhang, J., Lineaweaver, W. C., Oswald, T., Chen, Z., Chen, Z., and Zhang, F. (2004b). Ciliary neurotrophic factor for acceleration of peripheral nerve regeneration: an experimental study. J. Reconstr. Microsurg. 20, 323-327. doi: 10.1055/s-2004-824891

Zhang, J. Y., Luo, X. G., Xian, C. J., Liu, Z. H., and Zhou, X. F. (2000). Endogenous $\mathrm{BDNF}$ is required for myelination and regeneration of injured sciatic nerve in rodents. Eur. J. Neurosci. 12, 4171-4180. doi: 10.1111/j.1460-9568.2000. 01312.x

Zhang, L., Ma, Z., Smith, G. M., Wen, X., Pressman, Y., Wood, P. M., et al. (2009). GDNF-enhanced axonal regeneration and myelination following spinal cord injury is mediated by primary effects on neurons. Glia $57,1178-1191$. doi: 10.1002/glia.20840

Zhang, Y., Tatsuno, T., Carney, J. M., and Mattson, M. P. (1993). Basic FGF, NGF, and IGFs protect hippocampal and cortical neurons against iron-induced degeneration. J. Cereb. Blood Flow Metab. 13, 378-388. doi: 10.1038/jcbfm. 1993.51

Zheng, L. F., Wang, R., Yu, Q. P., Wang, H., Yi, X. N., Wang, Q. B., et al. (2010). Expression of $\mathrm{HGF} / \mathrm{c}-\mathrm{Met}$ is dynamically regulated in the dorsal root ganglions and spinal cord of adult rats following sciatic nerve ligation. Neurosignals 18 , 49-56. doi: 10.1159/000320715

Zhou, Z., Peng, X., Fink, D. J., and Mata, M. (2009). HSV-mediated transfer of artemin overcomes myelin inhibition to improve outcome after spinal cord injury. Mol. Ther. 17, 1173-1179. doi: 10.1038/mt.2009.52

Zhou, X. F., and Rush, R. A. (1993). Localization of neurotrophin-3-like immunoreactivity in peripheral tissues of the rat. Brain Res. 621, 189-199. doi: 10.1016/0006-8993(93)90106-w

Zhou, X. F., and Rush, R. A. (1996). Endogenous brain-derived neurotrophic factor is anterogradely transported in primary sensory neurons. Neuroscience 74, 945-951. doi: 10.1016/0306-4522(96)00237-0

Zochodne, D. W. (2008). Neurobiology of Peripheral Nerve Regeneratoin. New York, NY: Cambridge University Press.

Zochodne, D. W. (2012). The challenges and beauty of peripheral nerve regrowth. J. Peripher. Nerv. Syst. 17, 1-18. doi: 10.1111/j.1529-8027.2012.00378.x

Conflict of Interest Statement: The authors declare that the research was conducted in the absence of any commercial or financial relationships that could be construed as a potential conflict of interest.

Copyright (C) 2019 Duraikannu, Krishnan, Chandrasekhar and Zochodne. This is an open-access article distributed under the terms of the Creative Commons Attribution License (CC BY). The use, distribution or reproduction in other forums is permitted, provided the original author(s) and the copyright owner(s) are credited and that the original publication in this journal is cited, in accordance with accepted academic practice. No use, distribution or reproduction is permitted which does not comply with these terms. 